\title{
GAME THEORY BASED MULTI CRITERIA DECISION MAKING PROBLEM UNDER UNCERTAINTY: A CASE STUDY ON INDIAN TEA INDUSTRY
}

\author{
Animesh DEBNATH ${ }^{1}$, Abhirup BANDYOPADHYAY ${ }^{2}$, \\ Jagannath $\mathrm{ROY}^{3}$, Samarjit $\mathrm{KAR}^{4^{*}}$ \\ ${ }^{1}$ Department of Economics, Vivekananda Mahavidyalaya, Burdwan (East), 713103 India \\ 2, 3, 4 Department of Mathematics, National Institute of Technology, Durgapur, 713209 India
}

Received 12 April 2017; accepted 02 November 2017

\begin{abstract}
The long-term evolution of multi agent multi criteria decision making (MCDM) and to obtain sustainable decision a novel methodology is proposed based on evolutionary game theory. In this paper multi agent MCDM is represented as an evolutionary game and the evolutionary strategies are defined as sustainable decisions. Here we consider the problem of decision making in Indian Tea Industry. The agents in this game are essentially Indian Tea Estate owner and Indian Tea board. The replicator dynamics of the evolutionary game are studied to obtain evolutionary strategies which could be defined as sustainable strategies. The multi agent MCDM in Indian Tea Industry is considered under different socio-political and Corporate Social Responsibility scenario and groups of Indian Tea Industry. Again, the impacts of imprecision and market volatility on the outcome of some strategies (decisions) are studied. In this paper the imprecision on the impact of the strategies are modelled as fuzzy numbers whereas the market volatility is taken into account as white noise. Hence the MCDM problem for Indian Tea Industry is modelled as a hybrid evolutionary game. The probabilities of strategies are obtained by solving hybrid evolutionary game and could be represented as a Dempster-Shafer belief structure. The simulation results facilitate the Decision Makers to choose the strategies (decisions) under different type of uncertainty.
\end{abstract}

Keywords: MCDM in Indian Tea Industry, Evolutionary Game, Evolutionary stable strategies, Sustainable solution to MCDM, Uncertain Evolutionary game, Strategies under uncertainty, Sustainable development with CSR.

JEL Classification: C72, C73, D81, G34.

\section{Introduction}

Any multi agent MCDM problem involves simultaneous decision making which could be set-up as a game problem where the criteria and alternatives can be considered as strategies of the agents (players). MCDM is a method to select most convenient alternative among

${ }^{\star}$ Corresponding author. E-mail: kar_s_k@yahoo.com 
available ones with respect to some evaluation criteria fixed by the decision makers (DM) of a particular social problems (Debnath et al. 2017). Most of the MCDM methods recommend combining the aims of dissimilar DMs and altering the complex multi-objective decision making model into a single-objective model (Andreopoulou et al. 2017). In classical techniques of MCDM may not be sufficient to obtain an efficient (compromised or Pareto optimal) solution (in case of multi agent MCDM) or a satisfactory decision strategy in many industrial or engineering problems (Madani, Lund 2011). Consequently, when more than one agent interacts with their respective objectives, the classical MCDM problem could be extended to a strategic game theoretic model. Some of the relevant works can be found in the existing research work (Kang, Morin 2016; Aplak, Türkbey 2013; Deng et al. 2014; Mohanty, Gupta 2015). Although MCDM models (Roy et al. 2016a, 2016b, 2018; Debnath et al. 2017) serves good compromised solutions, it is found that many classical MCDM approaches overlook the behaviours of DMs. Evolutionary game theory provides evolutionary strategies which are sustainable solutions for the MCDM. In classical game theory, the strength of the Nash equilibrium concept rests upon three imperative assumptions (1) rational behaviour of agents (2) complete sharing of empirical information, (3) all the agents have common knowledge of these assumptions. The strictness of these assumptions leaves the Nash equilibrium vulnerable to criticism because we can simply consider circumstances where any or all of these assumptions cannot realistically be applied (Grant, Quiggin 2017). On the contrast evolutionary game theory compare the outcomes of all types of behaviours to identify which one sustains in the long run.

Concentrating on Indian Tea Estate (ITE), ninety percent of Tea production comes from - Assam, west Bengal, north and south India and the northeast region (Tirkey 2005). Almost all the researchers discussed multiple MCDM problems highlighting underutilization of tea growing area, declining of global demand, rising of international tea competitor, promotion of small tea growers and bought leaf sectors, marketplace loyalties of Indian tea sectors, low sociability or Corporate Social Responsibility CSR with underpaid labour etc (Kotler, Lee 2005). The existing CSR studies (Cheruiyot, Tarus 2017; Kotler, Lee 2005) diagnose the suitable factors for firms as well as the regulations of governments, international organizations and NGOs to motivate sustainable CSR developments; on the basis of different MCDM techniques. However this article explores evolutionary dynamics which illustrate the impact of different policies performed in the long run and identifies the sustainable factors to get ideal economic benefit with sustainable CSR activities. Also this study has assessed the CSR performance under uncertainties and complexities. The complexities of Indian Tea sector management are arising from clashes of contrasting interest of stakeholders and conflicts at different agents. Conflicts can happen at a local ground when numbers of ITE follow different attitudes in sociability or CSR in a same region or nationally, when Tea Development Authorities/ Indian Tea Board (ITB) in two states show different attitudes to developing the tea industry (Lazonick, O’Sullivan 2000).

The articulation of business strategies (or criteria) involving CSR after maintaining Indian Tea Board's (ITBs) multiple regulatory criteria (or strategies) and satisfying the market demand (national, international) is a huge challenge to tea industry. The current research work recommends a novel evolutionary game based approach for MCDM models and deals 
decision making under uncertain environments. The long-term evaluation of the repeated performance of the game is considered using evolutionary dynamics. The novelty of this research work can be stated as follows:

- An evolutionary game model is to study MCDM problems under certain and uncertain environments.

- This is the first attempt to model the MCDM problem in Indian Tea Industry (ITI) as an evolutionary game between the Tea Estate Owner (TEO) and ITB.

- The fuzzy evolutionary game and its dynamics are studied to obtain sustainable strategies in various geophysical and regional political scenarios.

The study presents a case study of decision making in the Tea Industry in India, where the outline of presenting MCDM models as Evolutionary strategic games is depicted. After that, a stochastic game model by means of Monte-Carlo simulation is framed for decision making under uncertainties manifested about the pay-off values. Also, the fuzzy stochastic game model is developed to deal with imprecision of outcome of strategies as well as market volatility.

\section{MCDM problem as a strategic game}

Typically, a MCDM problem with $m$ alternatives and $n$ criteria can be defined in the following form (Madani, Lund 2011).

$$
D=\left[\begin{array}{cccc}
\pi_{11} & \pi_{12} & \cdots & \pi_{1 n} \\
\pi_{21} & \pi_{22} & \cdots & \pi_{2 n} \\
\cdots & \cdots & \cdots & \cdots \\
\pi_{m 1} & \pi_{m 2} & \cdots & \pi_{m n}
\end{array}\right],
$$

where $\pi_{i j}$ is the performance of $i$ th alternative under the $j^{\text {th }}$ criterion for $i=1,2, \ldots, m$ and $j=1,2, \ldots, n$. Also, the relationship between an MCDM and a Game is depicted in Figure 1.

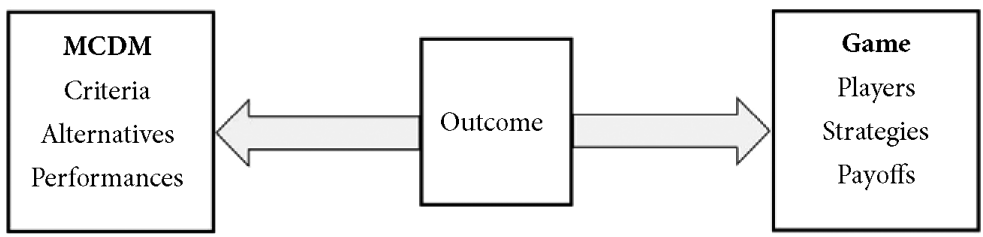

Figure 1. Relationship between an MCDM and a Game (Madani, Lund 2011)

The elementary aspects of an MCDM model are: (1) criteria (2) alternatives and (3) performances of alternatives for each criterion. These elements correspond to the primary rudiments of strategic game as (1) players (2) strategies and (3) payoffs of players from probable outcomes, where outcomes refer to all probable mixtures of players' strategies.

\section{Decision strategy selection under CSR perspective}

A MCDM model can be constructed by considering: (1) four alternatives to develop the estate with different ranges of CSR performance by tea owners and (2) five criteria of ITB are taken for proposed model. 


\subsection{Regulatory strategies setting for ITB}

ITI is the world's fourth largest Tea exporter, is losing ground to China as its domestic market grows (WTN 2016). In this study, Indian tea industries have been segregated into four groups $\left(G_{1}, G_{2}, G_{3}\right.$ and $\left.G_{4}\right)$ on the basis of geo-political-sociability condition at local level. Thus four "unmoved" group of tea industries are constructed as to manage multi-managerial dimensions of tea industry.

- Group $1\left(G_{1}\right)$ : GOOD geographical location (i.e. the ITE are in favourable weather condition that enhance the plant growth, no pollution effect etc.) and GOOD Regional political situation (i.e. All are parts of ethics, jointly follow the rules and regulation, collaborative preservation of safety, peace, and prosperity etc.)

- Group $2\left(G_{2}\right)$ : GOOD geographical location and BAD Regional political situation (i.e. immorality or biasness, tendency to break the rules and regulation, lack of preservation of safety, peace, and prosperity etc.)

- Group $3\left(G_{3}\right)$ : BAD geographical location (i.e. the ITE are in a volatile weather condition that prevent the plant growth, pollution effects the greenery etc.) and GOOD Regional political situation

- Group $4\left(G_{4}\right)$ : BAD geographical location and BAD Regional political situation

For instance, the ITE group under "BAD geographical location and GOOD Regional political situation" is always challenging (Bhattacharya, Sen 2001) due to conflicting interest on CSR progress and corruption level.

Due to the conflict between ITE and ITB on CSR based development; ITB employs a diverse attitude for different ITE groups. Depending upon estate's disturbances, overall gloomy scenario of inaction on bought leaf sectors, tea import and estate's capacity to control corruption (GW 2009) - ITB may chalk out various "altered” scenarios for regulatory purpose as:

- Scenario $1\left(S_{1}\right)$ : “Governance to current estate's disturbances": Disturbances can be solved by the changes of volume of sociability or CSR, and also the ITB may give higher weightage on certain criteria as long term policy.

- Scenario $2\left(S_{2}\right)$ : "Governance to control Bought Leaf sector and tea import": Development with CSR is possible under restricted or semi-open market policy in which criteria are the instrument to control the tea management.

- Scenario $3\left(S_{3}\right)$ : "Governance to estate's capacity progression under minimum corruption level": Estate's capacity can increase through changes on land usage pattern (e.g. attachment of highly demandable agricultural product plantation with tea) and tourism, while it can easily flourish under transparent management for sociability development.

- Scenario $4\left(S_{4}\right)$ : “Governance to estate's capacity progression under maximum corruption level": Lack of transparency and accountably (e.g. tea adulteration, misty earning vs. labour payment) will hamper any alternative system of development with criteria setting.

\subsection{Professional strategies of Indian Tea industries (ITI)}

Considering various levels of performance of sociability considered as alternatives of the tea industries' socio-economic development can be classified into four types. These alternatives are:

- Development with Praiseworthy CSR $\left(W_{1}\right)$ : Top most sociability and CSR performer (For example, "Makaibari" a model of developed ITE) as follows the features of "Com- 
mendable housing and rationing", "Creditable prosperity of education", "Admirable maintenance of labour policy" etc.

- Development with Pledge CSR $\left(W_{2}\right)$ : Grate initiator of CSR activity (e.g., "Glenburn" a developed ITE) as follows the characteristics of "Assurance of commendable housing and rationing", "undertaking of creditable prosperity of education", "Bond of Admirable maintenance of labour policy" etc.

- Development with Scattering CSR ( $\left.W_{3}\right)$ : Performer of scattered CSR activities (e.g., "Dunkun" ITE) as follows the faces of "Disperse from standard housing and rationing", "Dissipate of prosperity of education", "Disintegration of labour policy" etc. to develop the ITE.

- Development with Fatigue CSR ( $W_{4}$ ): Unwillingness to perform the CSR activity but running (e.g. "Bagrakota" ITE) with the features of 'Falling down of standard housing and rationing", "Listlessness to give prosperous education", "Lethargy to maintain the labour policy" etc.

Here the term "development" has considered as traditional in nature whereas the magnitude or outlook of CSR performances have been distinguished by the terms - Praiseworthy, Pledge, Scattered and Fatigue CSR. These are defined as the most important indicators of ITE development under different "unmoved" and "altered" scenarios (IT 2006).

\subsection{Professional strategies of ITB}

Considering the CSR based alternatives for tea industry development the criteria under multiple disciplines like economics, sociology, and political science perspectives (Cheruiyot, Tarus 2017), the study has proposed five criteria for ITB i.e.

- Safeguard of Satisfactory National and International Tea Demand $\left(R_{1}\right)$ : An effort to maximize the National and International Tea demand ITB need to ensure Tea quality care and control over tea import.

- Comprehensive Infrastructure of Tea Industry $\left(R_{2}\right)$ : Teacher-student ratio based schooling, quality medical treatment, electricity, and enriched housing facilities are examples of it.

- Inclusive Labour Policy $\left(R_{3}\right)$ : Sufficient rationing, Doctors Availability, proper PF-gratuity statement, hygiene issues.

- Wide-ranging assistance to ITE $\left(R_{4}\right)$ : For instance, subsidy for machinery import and loss of production as incentives for ITE.

- Ample Morality development $\left(R_{5}\right)$ : Minimizing the corruption of tea adulteration, financial ambiguity of the estate for the betterment of labours.

Under this various responsibilities, dimensions and disciplines for CSR performance, the tea industries till have lacked a strong ITB's institutional observation under various "unmoved" and "altered" scenarios to design precarious professional strategic decisions to converse this flagging situation and fulfil stakeholder's aspirations with strong interest of both players.

MCDM problem in tea industries may be modelled as follows. Under dissimilar "unmoved" and "altered" scenarios (as section 2.1), the MCDM model may be streamlined to four decision alternatives (as discussed in section 2.2) and five DMs (Eq. (1)). The objective of the problem is to select the optimal alternative for tea industries decision making groups with respect to different criteria (as in section 2.3). The ideal alternative would have the Substantive demand for tea, 
good infrastructure and sociability, logical assistance to the estate and zero level corruption. In order to frame the problem pay-off values in terms of linguistic form from Likert scale in crisp and fuzzy number (Table 1) comprise an uncertainty level for pay-offs.

\section{Evolutionary game theory}

Evolutionarily game theory was defined and introduced by Maynard and Price (1973) and further developed by Nowak and May (1992). The Nash equilibrium is the traditional solution concept in game theory. It depends on the cognitive abilities of the players (Nowak, Sigmund 2004; Requejo, Camacho 2011).

In the theory of evolutionary game the different pattern of behaviour of the agents of a game are considered and the behaviour which has the potential to overrule other forms of behaviour in the long run is studied.

The long term behaviour of evolutionary game is studied through its replicator dynamics as follows:

$$
\frac{d x_{i}}{d t}=x_{i}\left[f_{i}(x)-\varphi(x)\right], \varphi(x)=\sum_{i=1}^{n} x_{i} f_{i}(x),
$$

where $x_{i}$ is the proportion of type $\mathrm{i}^{\text {th }}$ behaviour in the population, and the distribution of $\mathrm{n}$ types are represented as the vector $x=\left(x_{1}, x_{2}, \ldots, x_{n}\right)$. Also $f_{i}(x)$ and $\varphi(x)$ are the fitness of type $i$ the average population fitness respectively. As $x_{i}$ are proportions and vector $x$ sum to unity the equation is defined on the $n$-dimensional simplex. The replicator equation assumes a uniform population distribution. If $A$ be the payoff matrix of the evolutionary game Eq. (2) can be written as:

$$
\frac{d x_{i}}{d t}=x_{i}\left[(A x)_{i}-x^{T} A x\right]
$$

where $(A x)_{i}$ is the expected payoff and $x^{T} A x$ be the mean fitness of the whole population. The state of the evolutionary game is specified by the fractions of each population currently employing. The state of the population in any time $t$ is represented by a probability $p$ of currently using the first mode, and 1-p of using the second mode (Hilbe 2011; Rosas 2010).

Table 1. Linguistic variables to describe relative outcomes and the Fuzzy scale value

\begin{tabular}{|l|c|c|}
\hline \multicolumn{1}{|c|}{ Linguistic variables to describe relative outcomes } & Likert Scale & Fuzzy scale \\
\hline Extremely High (EH) & 9 & $(7,9,9)$ \\
\hline Very Very high (VVH) & 7 & $(5,7,9)$ \\
\hline Very High (VH) & 5 & $(3,5,7)$ \\
\hline High (H) & 3 & $(1,3,5)$ \\
\hline Medium (ME) & 1 & $(1,1,3)$ \\
\hline Low (LO) & -3 & $(-5,-3,-1)$ \\
\hline Very Low (VL) & -5 & $(-7,-5,-3)$ \\
\hline Very Very Low (VVL) & -7 & $(-9,-7,-5)$ \\
\hline Extremely Low (EL) & -9 & $(-9,-9,-7)$ \\
\hline
\end{tabular}


Table 2. Pay-off matrix

\begin{tabular}{|c|c|c|c|c|c|}
\hline \multirow{2}{*}{$\begin{array}{c}\text { Strategy of Tea } \\
\text { Industry }\end{array}$} & \multicolumn{5}{|c|}{ Strategy of Government/Indian Tea Board } \\
\cline { 2 - 6 } & $R_{1}$ & $R_{2}$ & $R_{3}$ & $R_{4}$ & $R_{5}$ \\
\hline$W_{1}$ & $\pi_{T 1}$ & $\pi_{T 2}$ & $\pi_{T 3}$ & $\pi_{T 4}$ & $\pi_{T 5}$ \\
\hline$W_{2}$ & $\pi_{T 6}$ & $\pi_{T 7}$ & $\pi_{T 8}$ & $\pi_{T 9}$ & $\pi_{T 10}$ \\
\hline$W_{3}$ & $\pi_{T 11}$ & $\pi_{T 12}$ & $\pi_{T 13}$ & $\pi_{T 14}$ & $\pi_{T 15}$ \\
\hline$W_{4}$ & $\pi_{T 16}$ & $\pi_{T 17}$ & $\pi_{T 18}$ & $\pi_{T 19}$ & $\pi_{T 20}$ \\
\hline
\end{tabular}

\section{Representing MCDM as an evolutionary game}

The input payoff matrix of the evolutionary game perspective of tea production decision making problem, the tea industries strategies for development i.e. component $x_{i}\left(x_{i} \in X\right)$ are changing with time. Let $M$ be the pay-off matrix representing the expected outcome of the MCDM problem. Let $x_{i}$ and $y_{j}$ be the probabilities of $i$ th strategy of the TEO and $j^{\text {th }}$ strategy of tea board respectively. Then the replicator dynamics of the corresponding evolutionary game could be represented as

$$
\left\{\begin{array}{l}
\frac{d x_{i}}{d t}=x_{i}\left(G_{i}-F\right) \\
\frac{d y_{j}}{d t}=y_{j}\left(H_{j}-F\right),
\end{array}\right.
$$

where $G_{i}=\sum_{j=1}^{n} M_{i j} \times y_{j} ; H_{j}=\sum_{i=1}^{m} M_{i j} \times x_{i}$ and $F=\sum_{i=1}^{m} \sum_{j=1}^{n} M_{i j} \times x_{i} \times y_{j}$, Eq. (4) refer to the payoff functions of a tea industry who embraces diverse strategies. If the industry selects the development strategy with praiseworthy CSR performance, then its payoff functions are $\pi_{T 1}$, $\pi_{T 2}, \pi_{T 3}, \pi_{T 4}, \pi_{T 5}$; therefore the strategic development wise payoff matrix can be shown as Table 2.

In recent year few research works are published on uncertain game problem. Deng et al. (2016) and Deng et al. (2017) focused on the solution of games with Payoffs of DempsterShafer belief structures. Here in this problem the evolutionary dynamics is considered with stochastic payoff and imprecise (fuzzy) initial condition. Also the initial weightage of strategies at any circumstances is not precisely known on the basis of incomplete knowledge. This is modelled as triangular fuzzy numbers depending upon the expert opinion on current status of ITI.

Hence the decision problem in ITI could be modelled as Eqs. (4)-(5).

Here, the input payoff matrix $M$ is taken with $10 \%$ standard error with at least $95 \%$ of confidence level. i.e. $A=\left(I+\sigma W_{t}^{i j}\right) M$, where $\sigma=3 / 10$ and $W_{t}^{i j}$ denotes independent Wiener processes with $E\left(W_{t}^{i j}\right)=0$ and $\operatorname{Var}\left(W_{t}^{i j}\right)=E\left(\left(W_{t}^{i j}\right)^{2}\right)-E^{2}\left(W_{t}^{i j}\right)=t$. 
The replicator dynamics for the corresponding evolutionary game is solved numerically to obtain stable fixed points which are also evolutionary stable and mixed stable strategies or Nash equilibrium of the game. The stability of those fixed points are verified through local stability analysis and validated by the linier profile of the plots of evolution of strategies along with time.

For the sake of Monte Carlo simulation we have considered 1000 random iteration and the ensemble of the solution is obtained. Result obtained by MATLAB shows that there is no significant difference between mean and median as the ensemble with the linguistic payoff converted by nine point Likert scale (Table 1).

\section{Result and discussion}

\subsection{Representing MCDM as evolutionary game in deterministic form}

In the proposed simulation model, the tea management of industries has four strategies while the ITB has five strategies which leads to a $4 \times 5$ payoff matrix in linguistic scale (Table 3 ) constructed from four groups of industries for each of four scenarios. Thus, sixteen different clusters of simulation testing are performed, each cluster for nine strategies, as shown in separate parts for tea owners and tea board (Figures 2-13). In this four figures the evolution of strategies $W_{1}, W_{2}, W_{3}$ and $W_{4}$ are shown by green, red, deep blue and black curves respectively, whereas the evolution of strategies $R_{1}, R_{2}, R_{3}, R_{4}$ and $R_{5}$ are denoted by green, red, deep blue, black, cyan curves respectively.

(a) Here the deterministic system indicates there is no market volatility and no imprecision in terms of pay-off irrespective of balanced management of tea industry. The results depicted in Table 4, show that $W_{2}$ (for tea industry) and $R_{1}$ (ITB strategy) are ESS hence the Nash equilibrium of the MCDM problem under $S_{1}$ and $G_{1}$ (Figure 2a). In the same way, other groups also find their ESS. For $G_{2}, W_{1}$ is ESS for tea owner and mixed ESS for tea board with probability of $R_{1}$ and $R_{2}$ are 0.9987 and 0.13 respectively (Figure $2 \mathrm{~b}$ ). In case of $G_{3}$, tea owner as well as ITB are in a volatile position for their strategies implementation with $W_{1}, W_{2}$ and $R_{1}, R_{3}, R_{4}$ (Figure $2 \mathrm{c}$ ). And for $G_{4} ; W_{2}$ and $R_{1}$ are found to be ESS (Figure 2d).

(b) In case of $S_{2}$ (Figure 3), for this system the $W_{2}$ and $R_{5}$ converge to the ESS $(1,1)$ for $G_{1}$ tea industries who implement the $W_{2}$ strategic development with $R_{5}$ ITBs strategy and make balance management with CSR (3a). Similarly, $W_{2}$ and $R_{5}$ for $G_{2}, W_{1}$ and $R_{4}$ for $G_{3}$ converges to ESS (3b, 3c). Finally, for $G_{4}$, the system finds mixed strategy as $W_{1}, W_{2}$ for tea owner and $R_{1}, R_{4}$ for ITB. All the strategies are used for CSR activity (3d).

(c) For $S_{3}$ (Figure 4), the $W_{1}$ and $R_{1}$ converge to the ESS $(1,1)$ for the $G_{1}$ tea industries (4a). In the same way, other groups also find their suitable strategies. However, the other strategies ( $W_{2}, W_{3}, W_{4}, R_{2}, R_{3}, R_{4}, R_{5}$ ) for $G_{1}$, reflect different convergence tendencies with initial settings for scenario 4 (a) and drops to ESS $(0,0)$. For $G_{2}, W_{3}$ is a stable strategy of industry and thus ITBs playing strategy $R_{5}(4 \mathrm{~b})$. In case of $G_{3}$, tea owners are in a volatile position for their strategies implementation with $W_{2}, W_{3}, W_{4}$ and ITB with $R_{1}$ (4c). And for $G_{4}$, stability may persist with $W_{1}$ for tea owner while, ITB is stacked to $R_{5}(4 \mathrm{~d})$. 
Table 3. Pay-off matrix under $S_{1}-G_{1}$

\begin{tabular}{|c|c|c|c|c|c|c|}
\hline \multicolumn{2}{|c|}{$\begin{array}{c}\text { Probability } \\
\boldsymbol{V}\end{array}$} & $P\left(R_{1}\right)$ & $P\left(R_{2}\right)$ & $P\left(R_{3}\right)$ & $P\left(R_{4}\right)$ & $P\left(R_{5}\right)$ \\
\cline { 3 - 7 } & $R_{1}$ & $R_{2}$ & $R_{3}$ & $R_{4}$ & $R_{5}$ \\
\hline$P\left(W_{1}\right)$ & $W_{1}$ & $\mathrm{VVH}$ & $\mathrm{ME}$ & $\mathrm{H}$ & $\mathrm{ME}$ & $\mathrm{H}$ \\
\hline$P\left(W_{2}\right)$ & $W_{2}$ & $\mathrm{VVH}$ & $\mathrm{ME}$ & $\mathrm{H}$ & $\mathrm{ME}$ & $\mathrm{ME}$ \\
\hline$P\left(W_{3}\right)$ & $W_{3}$ & $\mathrm{VH}$ & $\mathrm{ME}$ & $\mathrm{LO}$ & $\mathrm{LO}$ & $\mathrm{LO}$ \\
\hline$P\left(W_{4}\right)$ & $W_{4}$ & $\mathrm{H}$ & $\mathrm{ME}$ & $\mathrm{VL}$ & $\mathrm{LO}$ & $\mathrm{VL}$ \\
\hline
\end{tabular}

Table 4. The deterministic pay-off value

\begin{tabular}{|c|c|c|c|c|c|c|c|c|c|}
\hline & \multicolumn{4}{|c|}{ Tea industry } & \multicolumn{5}{|c|}{ Government/ Indian Tea Board } \\
\hline & $W_{1}$ & $W_{2}$ & $W_{3}$ & $W_{4}$ & $R_{1}$ & $R_{2}$ & $R_{3}$ & $R_{4}$ & $R_{5}$ \\
\hline $2(\mathrm{a})$ & 0.0000 & 1.0000 & 0.0000 & 0.0000 & 1.0000 & 0.0000 & 0.0000 & 0.0000 & 0.0000 \\
\hline $2(\mathrm{~b})$ & 1.0000 & 0.0000 & 0.0000 & 0.0000 & 0.9987 & 0.0013 & 0.0000 & 0.0000 & 0.0000 \\
\hline $2(c)$ & 0.7418 & 0.2582 & 0.0000 & 0.0000 & 0.8216 & 0.0000 & 0.1568 & 0.0216 & 0.0000 \\
\hline $2(d)$ & 0.0012 & 0.9916 & 0.0057 & 0.0015 & 1.0000 & 0.0000 & 0.0000 & 0.0000 & 0.0000 \\
\hline $3(\mathrm{a})$ & 0.0000 & 1.0000 & 0.0000 & 0.0000 & 0.0000 & 0.0000 & 0.0000 & 0.0000 & 1.0000 \\
\hline $3(b)$ & 0.0000 & 1.0000 & 0.0000 & 0.0000 & 1.0000 & 0.0000 & 0.0000 & 0.0000 & 0.0000 \\
\hline $3(c)$ & 1.0000 & 0.0000 & 0.0000 & 0.0000 & 0.0000 & 0.0000 & 0.0000 & 1.0000 & 0.0000 \\
\hline $3(d)$ & 0.0144 & 0.9856 & 0.0000 & 0.0000 & 0.5231 & 0.0000 & 0.0000 & 0.4769 & 0.0000 \\
\hline $4(\mathrm{a})$ & 1.0000 & 0.0000 & 0.0000 & 0.0000 & 1.0000 & 0.0000 & 0.0000 & 0.0000 & 0.0000 \\
\hline $4(b)$ & 0.0002 & 0.0000 & 0.9998 & 0.0000 & 0.0000 & 0.0000 & 0.0000 & 0.0000 & 1.0000 \\
\hline $4(c)$ & 0.0000 & 0.3977 & 0.5939 & 0.0084 & 0.9971 & 0.0000 & 0.0000 & 0.0000 & 0.0029 \\
\hline $4(d)$ & 1.0000 & 0.0000 & 0.0000 & 0.0000 & 0.0000 & 0.0000 & 0.0000 & 0.0000 & 1.0000 \\
\hline $5(a)$ & 1.0000 & 0.0000 & 0.0000 & 0.0000 & 1.0000 & 0.0000 & 0.0000 & 0.0000 & 0.0000 \\
\hline $5(b)$ & 0.0000 & 1.0000 & 0.0000 & 0.0000 & 0.0000 & 0.0000 & 0.0000 & 1.0000 & 0.0000 \\
\hline $5(c)$ & 0.6672 & 0.0004 & 0.0000 & 0.3324 & 1.0000 & 0.0000 & 0.0000 & 0.0000 & 0.0000 \\
\hline $5(d)$ & 0.0000 & 1.0000 & 0.0000 & 0.0000 & 0.0000 & 0.0000 & 0.0000 & 1.0000 & 0.0000 \\
\hline
\end{tabular}

(d) In the $S_{4}$ (Figure 5), $W_{1}$ and $R_{1}$ converge to the ESS $(1,1)$ for the $G_{1}(5 \mathrm{a})$. For $G_{2}$, tea industry has strong probability to choose $W_{2}$ while ITB to emphasize on $R_{4}$ for CSR based strategic development (5b). In case of $G_{3}$, tea owner chooses mixed strategy with $W_{1}$ and $W_{4}$ while, ITB is stick to implement strategy $R_{1}(5 \mathrm{c})$. And for $G_{4}$, ESS is found with $W_{2}$ for tea owner while, $R_{4}$ is for ITB strategy. 

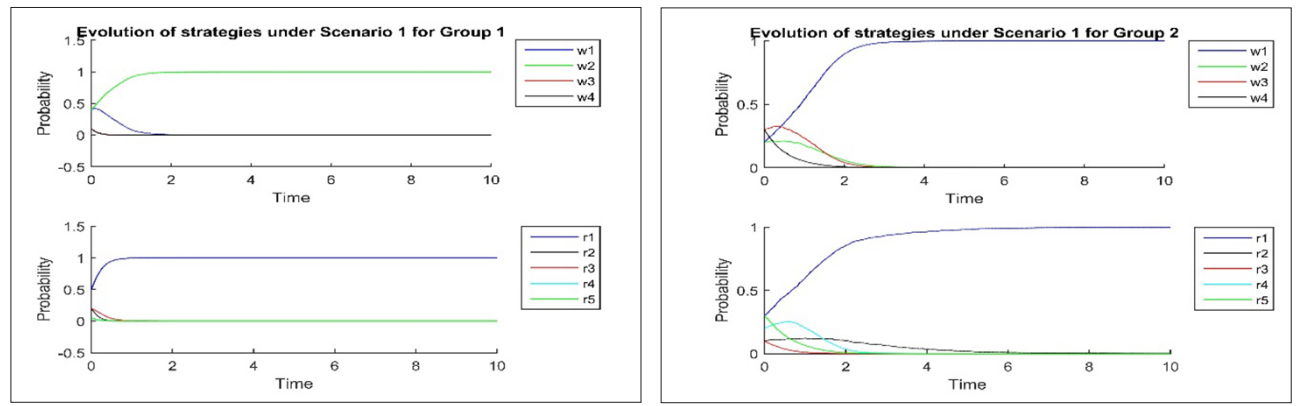

2a)
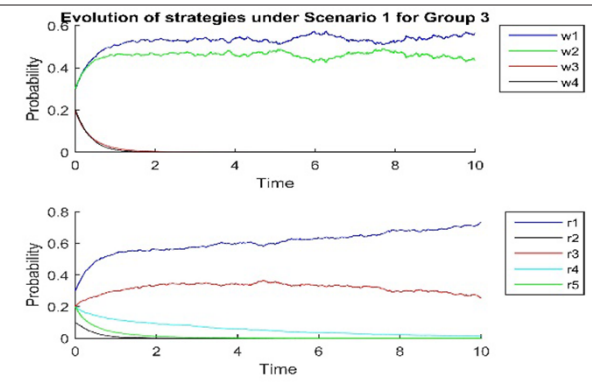

2c) 2b)

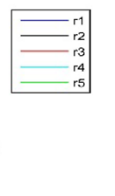

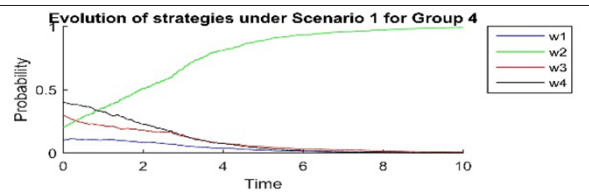
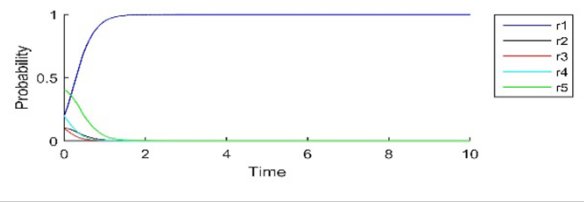

2d)

Figure 2. The crisp evolutionary process for $G_{1}, G_{2}, G_{3}, G_{4}$ under $S_{1}$
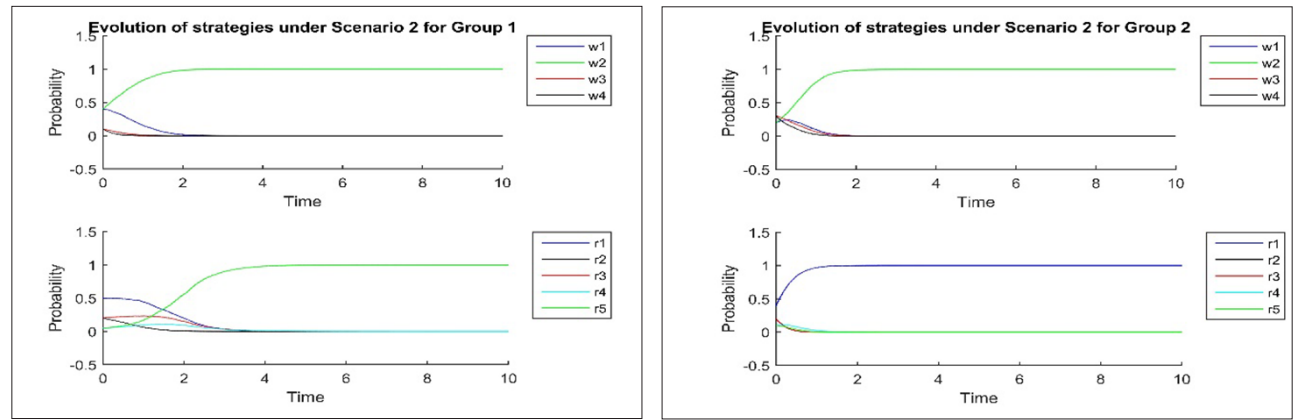

3a)

3b)
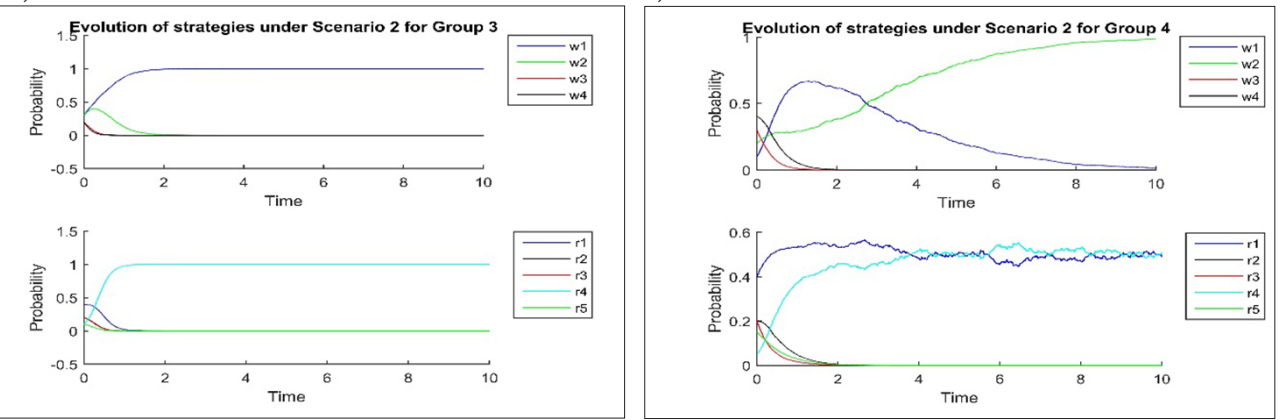

$3 \mathrm{~d})$

Figure 3. The crisp evolutionary process for $G_{1}, G_{2}, G_{3}, G_{4}$ under $S_{2}$ 


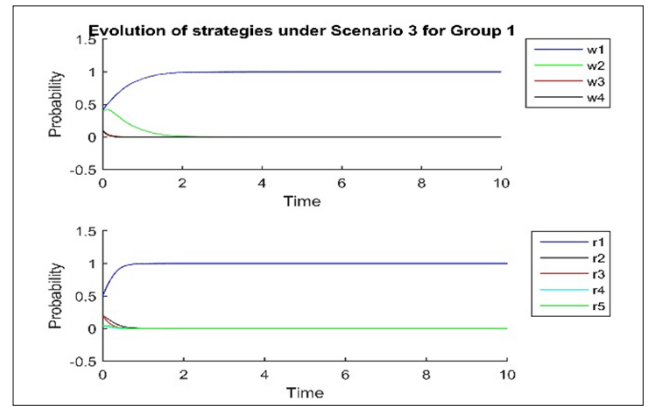

4a)
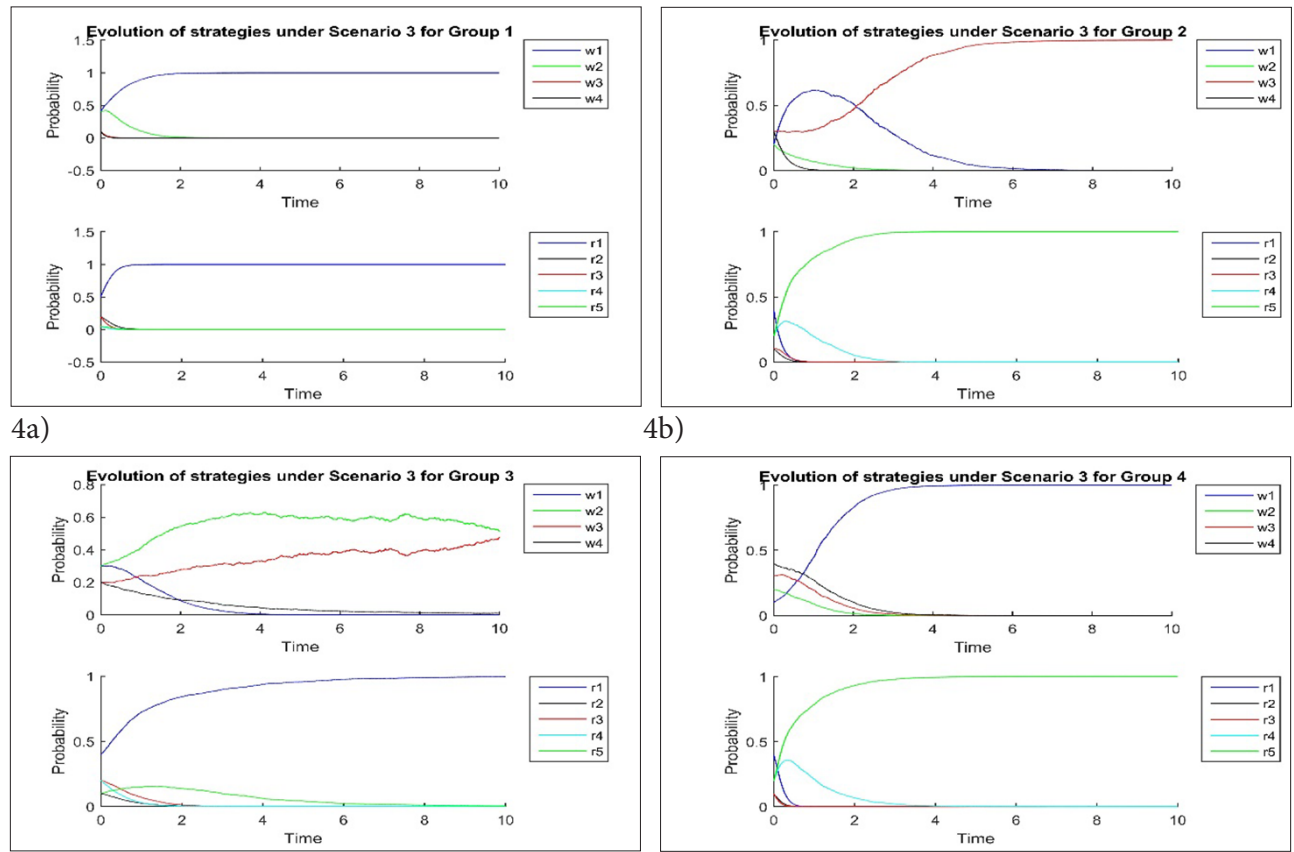

4b)

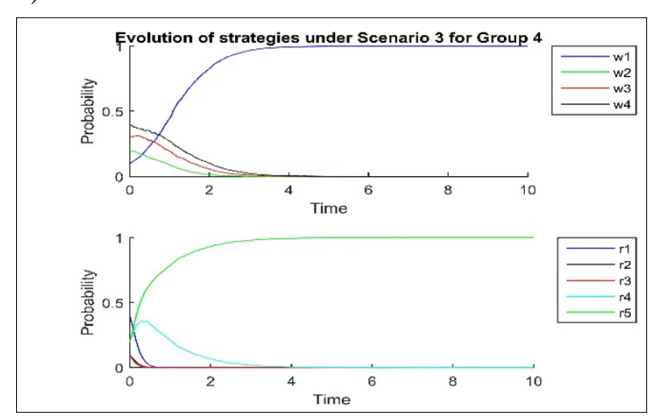

4d)

Figure 4 . The crisp evolutionary process for $G_{1}, G_{2}, G_{3}, G_{4}$ under $S_{3}$

\subsection{Representing MCDM as evolutionary game in imprecise nature}

(a) In this case the fuzzy variables are represented as the imprecise effect of different strategies under pay-off matrix for the balance management of tea industry. From the above analysis it is observed that for $S_{1}, G_{2}$ the most favourable strategies are $W_{1}, W_{2}$ and $W_{3}$ with probabilities $[0.2755,0.2784],[0.2755,0.2784]$ and $[0.4132,0.4176]$ respectively for the tea industry management and $R_{1}, R_{2}, R_{3}$ and $R_{4}$ with probabilities [0.4132, 0.4176], [0.1377, 0.1392], [0.1377, 0.1392] and [0.2755, 0.2784] respectively as shown in Table 6 and Figure 6 (6b). Similarly, same strategies are favourable for $G_{1}(6 \mathrm{a}), G_{3}(6 \mathrm{c})$ and $G_{4}(6 \mathrm{~d})$.

(b) For $S_{2}$, both $G_{1}$ and $G_{2}$ shows the deterministic strategy i.e. $W_{4}$ and $R_{5}$ for estate owner and tea board $(7 \mathrm{a}, 7 \mathrm{~b})$. While for $G_{3}$ under same scenario, it is observed that all four strategies $\left(W_{1}, W_{2}, W_{3}\right.$ and $\left.W_{4}\right)$ of owner of the tea garden are favourable with probabilities [0.3306, 0.3332], [0.3306, 0.3332], [0.2204, 0.2221] and [0.1114, 0.1175] respectively, the ITB have $R_{1}, R_{2}, R_{3}$ and $R_{4}$ with probabilities [0.441,0.444], [0.2204, 0.2221], [0.2204, 0.2221] and $[0.1102,0.1111]$ respectively represented in $7 \mathrm{c}$ of Figure 7.

(c) The imprecision in effect of different strategies in terms of balance management of tea industry both owner and ITB performs strategies $W_{4}$ and $R_{5}$ like the cases as in deterministic nature under $S_{3}$ for all groups (Figure 8).

(d) For $S_{4}$, it is seen that $G_{3}$ have most favourable strategies as $W_{1}, W_{2}$ and $W_{3}$ with probabilities [0.3692, 0.3709], [0.3692, 0.3709] and [0.2462, 0.2473] respectively and $R_{1}, R_{2}$, $R_{3}$ and $R_{4}$ with probabilities [0.369, 0.371], [0.1231, 0.1236], [0.2462, 0.2473] and [0.2463, 0.2473 ] respectively as shown in Figure 9c. Similarly, same strategies are favourable for $G_{1}$ (9a), $G_{2}(9 \mathrm{~b})$ and $G_{4}(9 \mathrm{~d})$. 

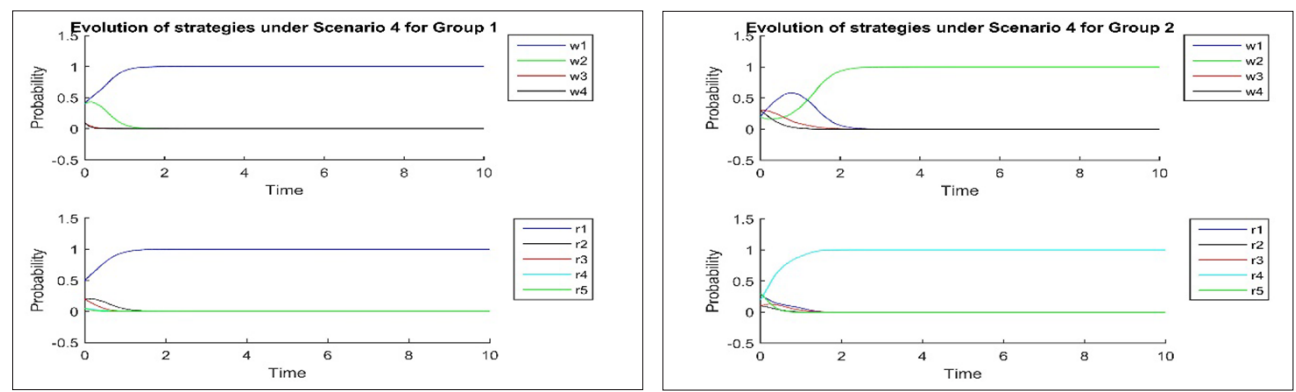

5a)

5b)
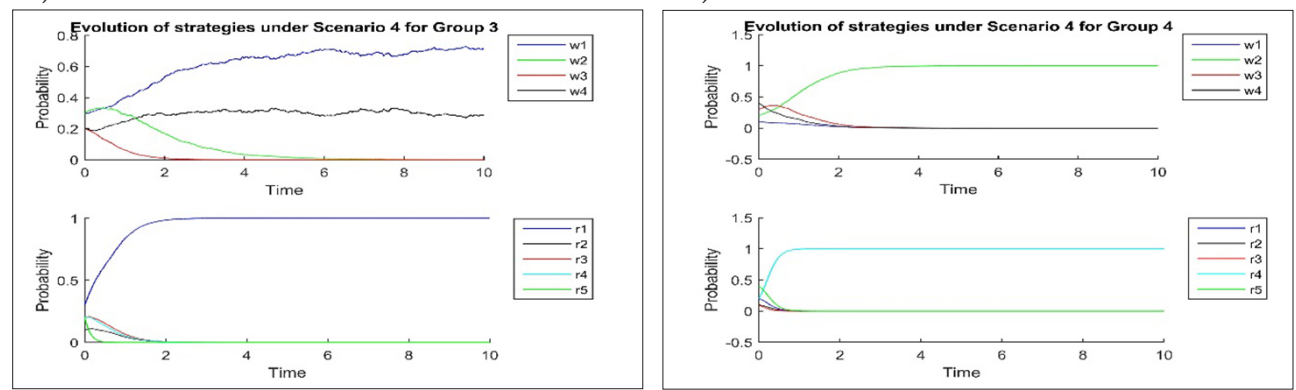

5c)

$5 d)$

Figure 5. The crisp evolutionary process for $G_{1}, G_{2}, G_{3}, G_{4}$ under $S_{4}$

Table 5. Evolutionary probability of different strategies with imprecise impact of strategy interaction under $S_{1}-G_{2}$ for different $\alpha$-cut

\begin{tabular}{|c|c|c|c|c|c|c|c|c|c|c|}
\hline$\alpha$-value & & $W_{1}$ & $W_{2}$ & $W_{3}$ & $W_{4}$ & $R_{1}$ & $R_{2}$ & $R_{3}$ & $R_{4}$ & $R_{5}$ \\
\hline \multirow{2}{*}{0} & Lower & 0.2755 & 0.2755 & 0.4132 & 0.0257 & 0.4132 & 0.1377 & 0.1377 & 0.2755 & 0.026 \\
\cline { 2 - 10 } & Upper & 0.2784 & 0.2784 & 0.4176 & 0.0351 & 0.4176 & 0.1392 & 0.1392 & 0.2784 & 0.035 \\
\hline \multirow{3}{*}{0.2} & Lower & 0.2757 & 0.2757 & 0.4135 & 0.0269 & 0.4135 & 0.1378 & 0.1378 & 0.2757 & 0.027 \\
\cline { 2 - 11 } & Upper & 0.278 & 0.278 & 0.417 & 0.0344 & 0.417 & 0.139 & 0.139 & 0.278 & 0.034 \\
\hline \multirow{3}{*}{0.4} & Lower & 0.2759 & 0.2759 & 0.4138 & 0.0282 & 0.4138 & 0.1379 & 0.1379 & 0.2759 & 0.028 \\
\cline { 2 - 11 } & Upper & 0.2776 & 0.2776 & 0.4165 & 0.0338 & 0.4165 & 0.1388 & 0.1388 & 0.2776 & 0.034 \\
\hline \multirow{3}{*}{0.6} & Lower & 0.2761 & 0.2761 & 0.4141 & 0.0297 & 0.4141 & 0.138 & 0.138 & 0.2761 & 0.03 \\
\cline { 2 - 10 } & Upper & 0.2772 & 0.2772 & 0.4158 & 0.0331 & 0.4158 & 0.1386 & 0.1386 & 0.2772 & 0.033 \\
\hline \multirow{2}{*}{0.8} & Lower & 0.2763 & 0.2763 & 0.4144 & 0.0313 & 0.4144 & 0.1381 & 0.1381 & 0.2763 & 0.031 \\
\cline { 2 - 10 } & Upper & 0.2768 & 0.2768 & 0.4152 & 0.0325 & 0.4152 & 0.1384 & 0.1384 & 0.2768 & 0.033 \\
\hline \multirow{2}{*}{1} & Lower & 0.2764 & 0.2764 & 0.4146 & 0.0325 & 0.4146 & 0.1382 & 0.1382 & 0.2764 & 0.033 \\
\cline { 2 - 10 } & Upper & 0.2764 & 0.2764 & 0.4146 & 0.0325 & 0.4146 & 0.1382 & 0.1382 & 0.2764 & 0.033 \\
\hline
\end{tabular}




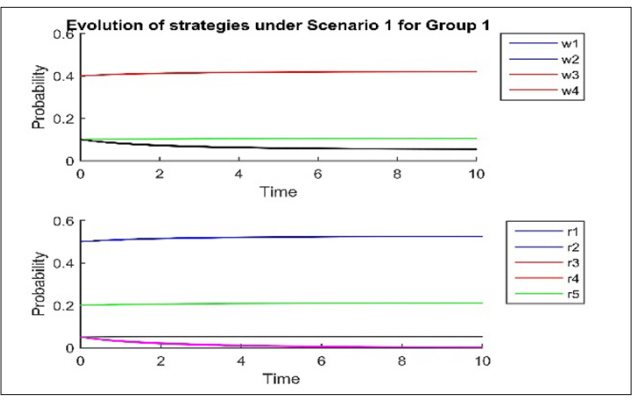

6a)

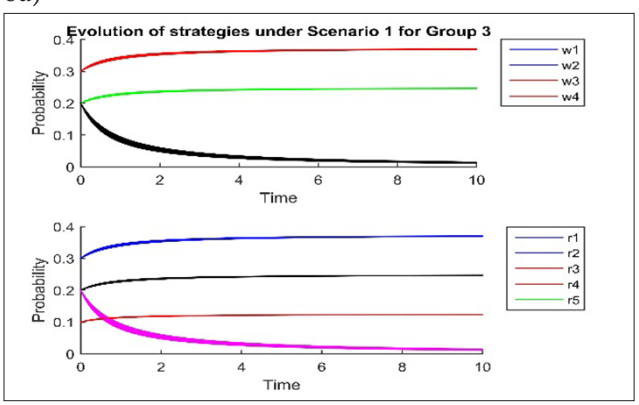

6c)

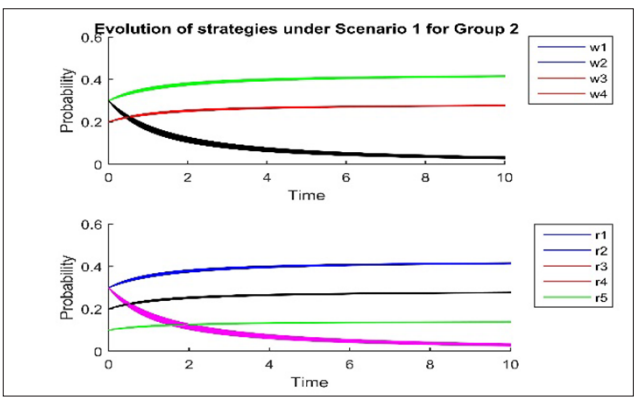

6b)

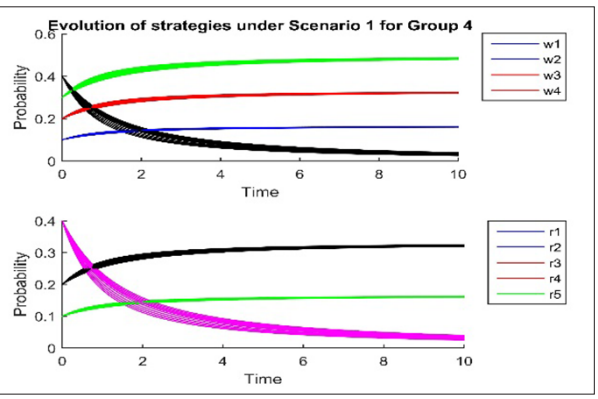

6d)

Figure 6. The imprecise evolutionary process for $G_{1}, G_{2}, G_{3}, G_{4}$ under $S_{1}$

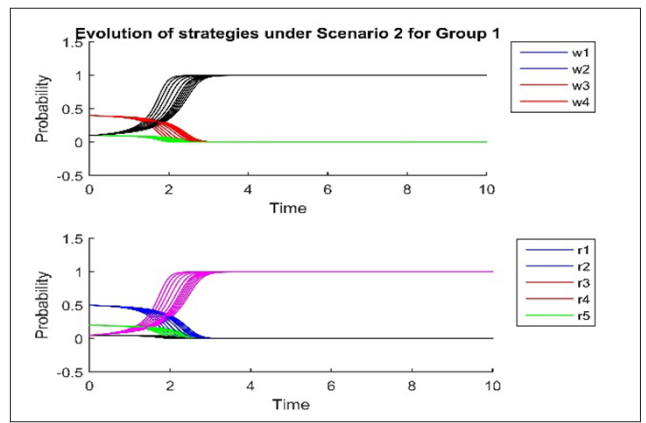

7a)

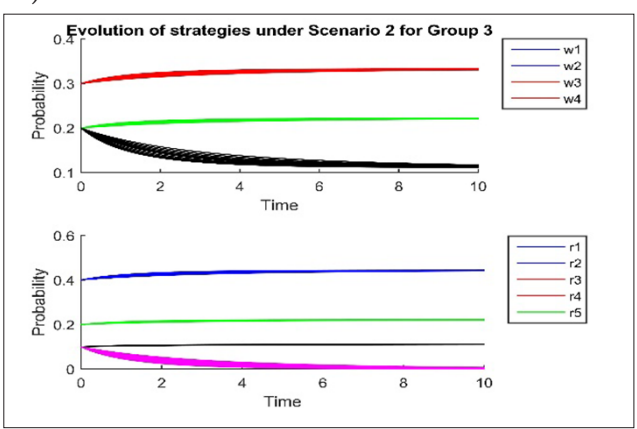

7c)

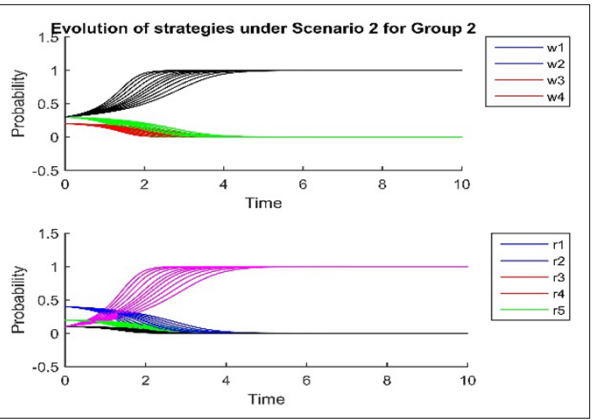

7b)

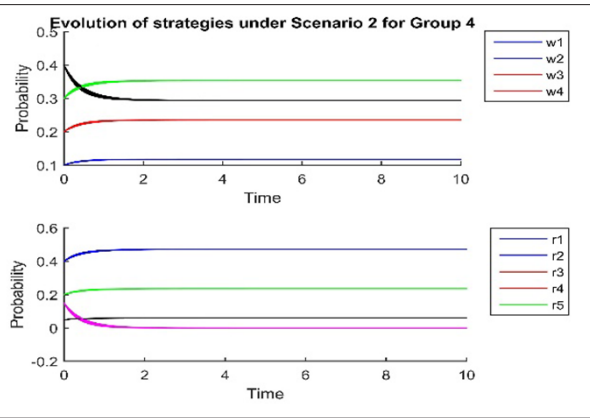

7d)

Figure 7. The imprecise evolutionary process for $G_{1}, G_{2}, G_{3}, G_{4}$ under $S_{2}$ 


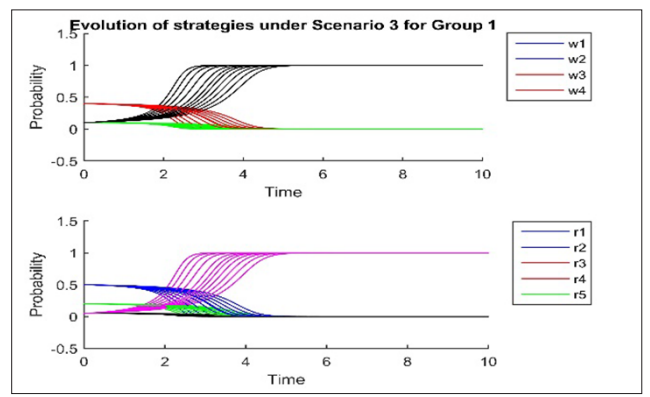

8a)
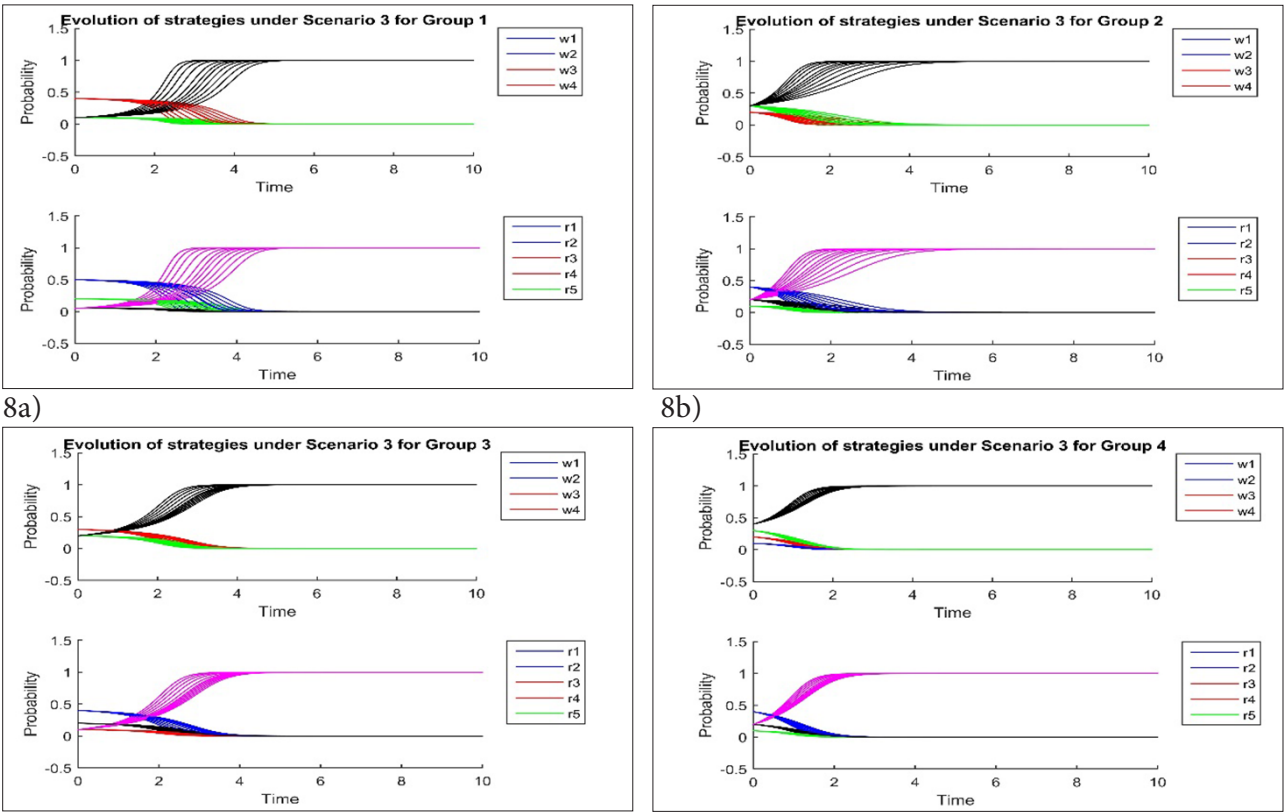

8c)

8b)

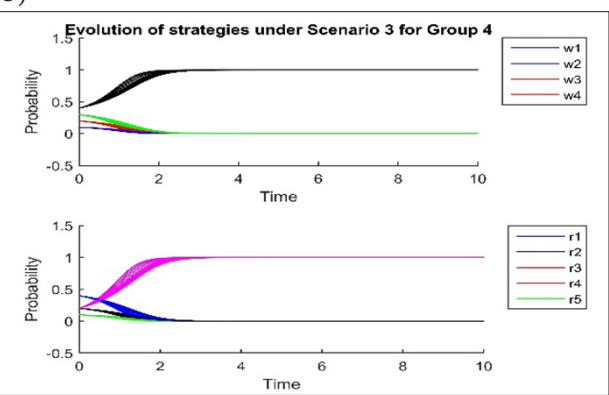

$8 d)$

Figure 8 . The imprecise evolutionary process for $G_{1}, G_{2}, G_{3}, G_{4}$ under $S_{3}$

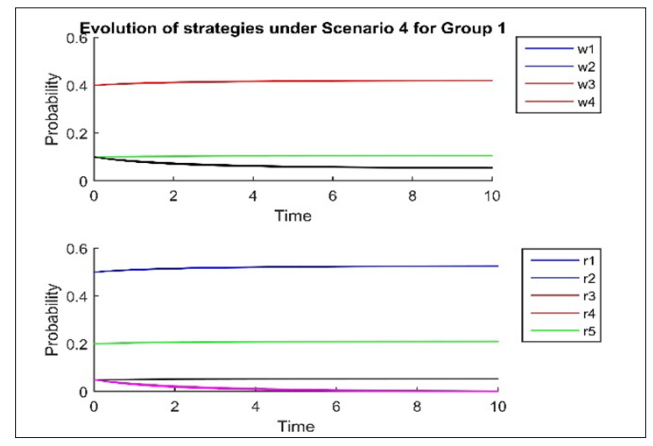

9a)
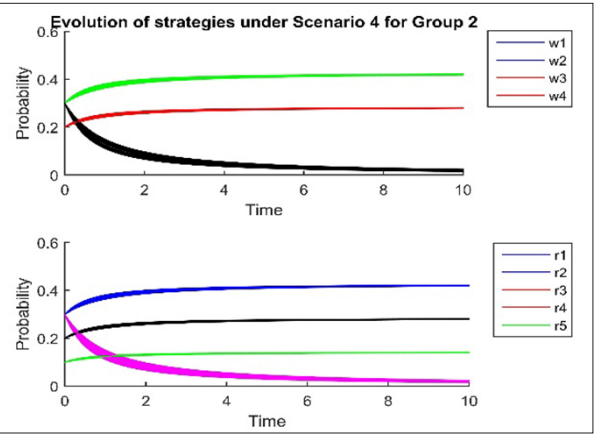

9b)
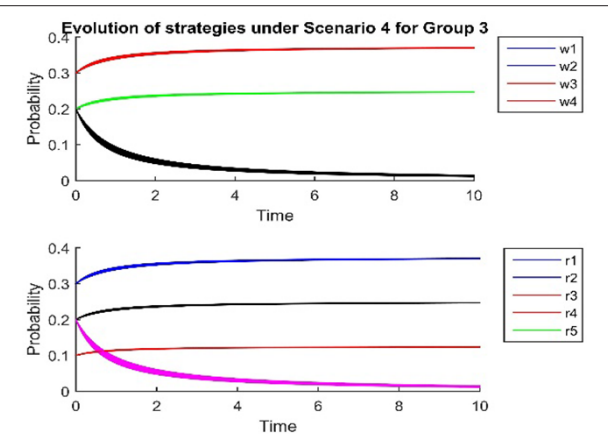

9c)

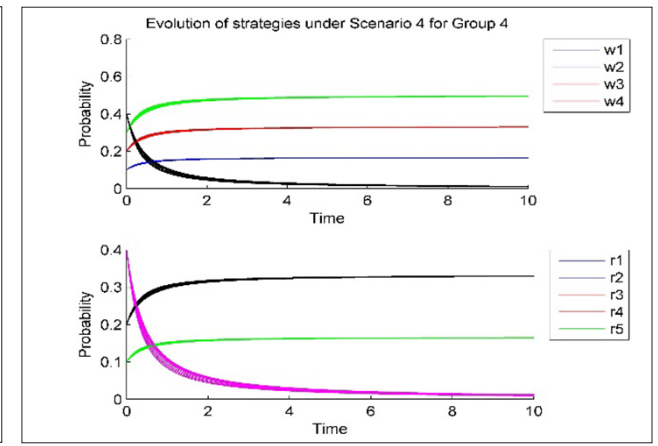

9d)

Figure 9. The imprecise evolutionary process for $G_{1}, G_{2}, G_{3}, G_{4}$ under $S_{4}$ 


\subsection{Representing MCDM as evolutionary game in fuzzy stochastic nature}

(a) The fuzzy stochastic model considers the scenario where there is imprecision on the impact of different strategies as well as market volatility. In this case it is observed that for $S_{1}$, the $G_{4}$ have the most favourable strategies as $W_{1}, W_{2}$ and $W_{3}$ with probabilities [0.0917, $0.1674],[0.1959,0.3639]$ and $[0.3118,0.5518]$ respectively for the tea industry management and $R_{1}, R_{2}, R_{3}$ and $R_{4}$ with probabilities [0.2011, 0.3722], [0.0867, 0.1657], [0.0805, 0.2341] and $[0.2013,0.3097]$ respectively as shown in Table 7, Figure 10d. Similarly, same strategies are favourable for $G_{1}(10 \mathrm{a}), G_{2}(10 \mathrm{~b})$ and $W_{2}(10 \mathrm{c})$.

(b) Here, the fuzzy stochastic model considers the scenario where there is imprecision on the impact of different strategies as well as market volatility. From the above analysis it is observed that for $G_{4}, G_{3}$ the most favourable strategies are $G_{1}, G_{2}, W_{3}$ and $W_{4}$ with probabilities [0.2035, 0.3271], [0.2065, 0.3619], [0.1325, 0.2484] and [0.0547, 0.123] respectively for the tea industry management and $R_{1}, R_{2}, R_{4}$ and $R_{1}$ with probabilities [0.3049, 0.4921], $[0.1094,0.2318],[0.1299,0.2418]$ and $[0.0631,0.1307]$ respectively as shown in Figure 11c.

(c) In $S_{3}$, the fuzzy stochastic model in effect of different strategies and market volatility for balance management of tea industry, both owner and ITB performs strategies $W_{4}$ and $R_{5}$ as like deterministic in nature for every scenarios and groups as in Figure 12.

(d) For this model it is observed that for $S_{4}$, the $G_{4}$ have the most favourable strategies are $R_{1}, W_{2}$ and $W_{3}$ with probabilities [0.0897, 0.2061], [0.2102, 0.392] and [0.337, 0.4938] respectively for the tea industry management and $G_{2}, G_{4}, R_{1}$ and $R_{3}$ with probabilities [0.1942, 0.4149], [0.0898, 0.2267], [0.0841, 0.1722] and [0.1829, 0.3403] respectively as shown in Table 7, Figure 13d.

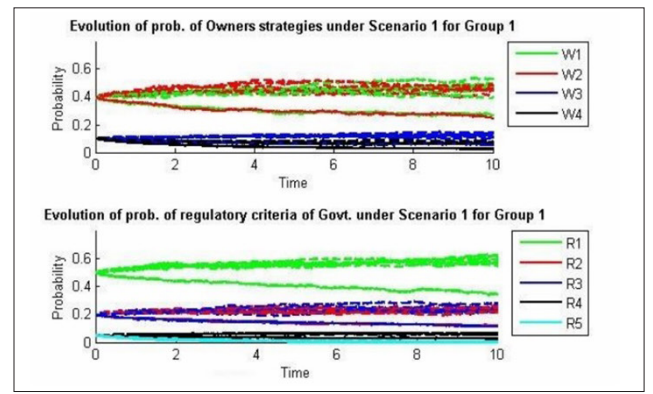

10a)
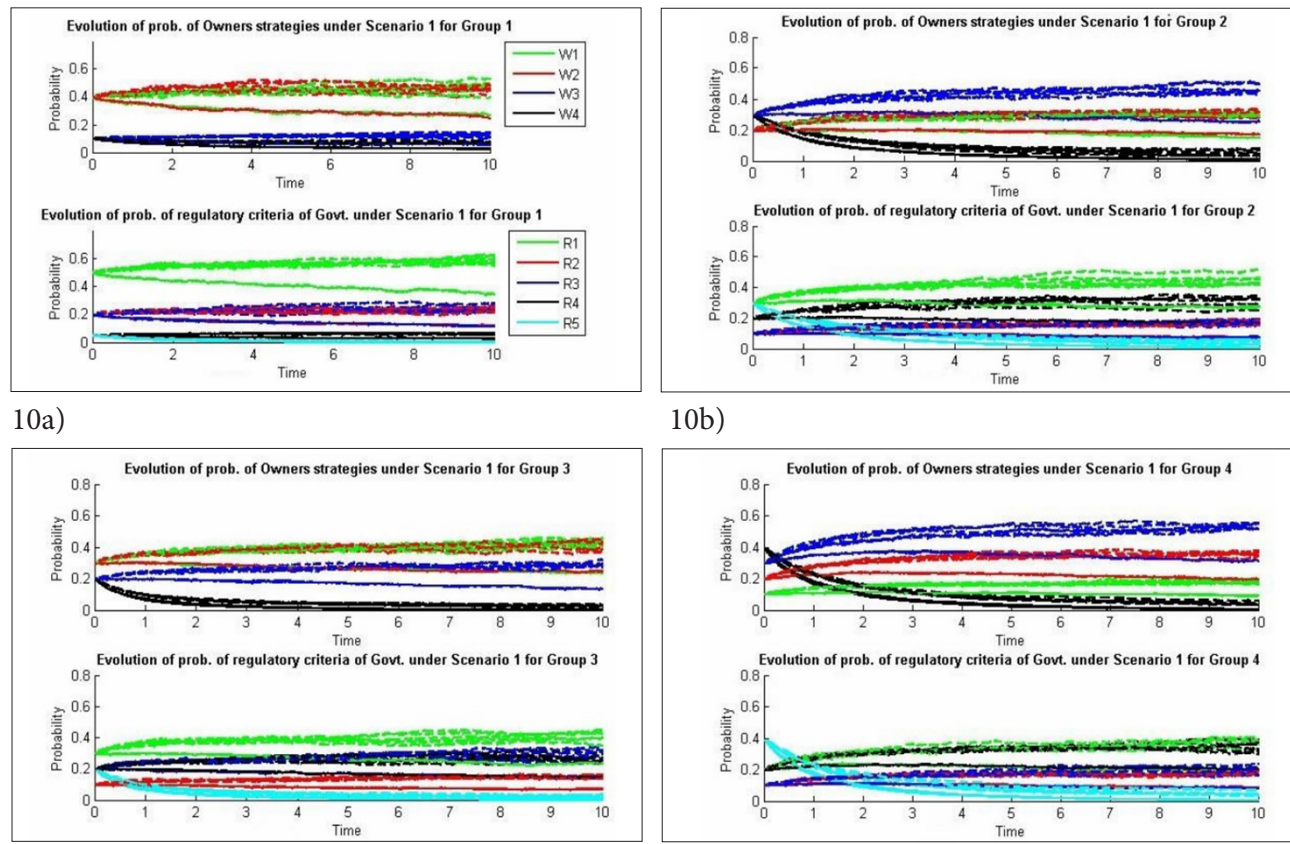

10c)

$10 \mathrm{~b})$

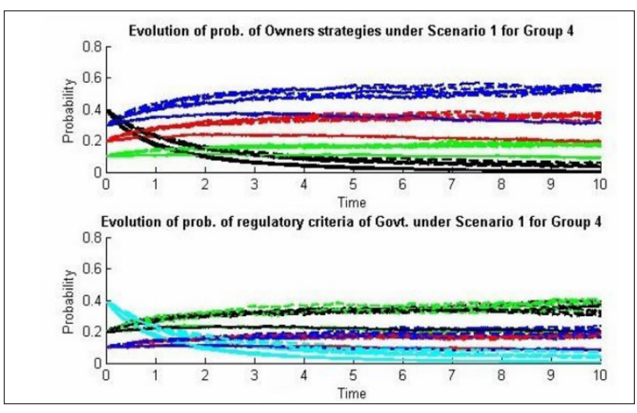

10d)

Figure 10. The fuzzy stochastic evolutionary process for $G_{1}, G_{2}, G_{3}, G_{4}$ under $S_{1}$ 
Table 6. Evolutionary probability of different strategies with imprecise impact of strategy interaction and market volatility under $S_{1}-G_{2}$ for different $\alpha$-cut

\begin{tabular}{|c|c|c|c|c|c|c|c|c|c|c|}
\hline$\alpha$-value & & $W_{1}$ & $W_{2}$ & $W_{3}$ & $W_{4}$ & $R_{1}$ & $R_{2}$ & $R_{3}$ & $R_{4}$ & $R_{5}$ \\
\hline \multirow{2}{*}{0} & Lower & 0.0897 & 0.2102 & 0.3370 & 0.0003 & 0.1942 & 0.0898 & 0.0841 & 0.1829 & 0.0003 \\
\cline { 2 - 10 } & Upper & 0.2061 & 0.3920 & 0.4938 & 0.0285 & 0.4149 & 0.2267 & 0.1722 & 0.3403 & 0.0288 \\
\hline \multirow{2}{*}{0.2} & Lower & 0.0897 & 0.2102 & 0.3370 & 0.0003 & 0.2068 & 0.0898 & 0.0841 & 0.1829 & 0.0003 \\
\cline { 2 - 11 } & Upper & 0.2196 & 0.3843 & 0.5593 & 0.0199 & 0.3965 & 0.1830 & 0.1740 & 0.3551 & 0.0173 \\
\hline \multirow{2}{*}{0.4} & Lower & 0.0897 & 0.2126 & 0.3370 & 0.0003 & 0.2068 & 0.0898 & 0.0841 & 0.1829 & 0.0003 \\
\cline { 2 - 10 } & Upper & 0.2345 & 0.3812 & 0.5301 & 0.0187 & 0.3765 & 0.1477 & 0.1799 & 0.3378 & 0.0238 \\
\hline \multirow{3}{*}{0.6} & Lower & 0.0897 & 0.2126 & 0.3370 & 0.0003 & 0.2068 & 0.0898 & 0.0841 & 0.1829 & 0.0003 \\
\cline { 2 - 10 } & Upper & 0.1844 & 0.3408 & 0.5567 & 0.0402 & 0.3557 & 0.2364 & 0.1763 & 0.3626 & 0.0278 \\
\hline \multirow{2}{*}{0.8} & Lower & 0.0897 & 0.2126 & 0.3370 & 0.0003 & 0.2068 & 0.0898 & 0.0841 & 0.1829 & 0.0003 \\
\cline { 2 - 10 } & Upper & 0.1770 & 0.3514 & 0.5366 & 0.0338 & 0.4308 & 0.1808 & 0.1963 & 0.3766 & 0.0229 \\
\hline \multirow{2}{*}{1} & Lower & 0.0897 & 0.2126 & 0.3370 & 0.0003 & 0.2068 & 0.0898 & 0.0841 & 0.1829 & 0.0003 \\
\cline { 2 - 10 } & Upper & 0.1659 & 0.3993 & 0.5383 & 0.0223 & 0.3565 & 0.1978 & 0.2019 & 0.3632 & 0.0191 \\
\hline
\end{tabular}

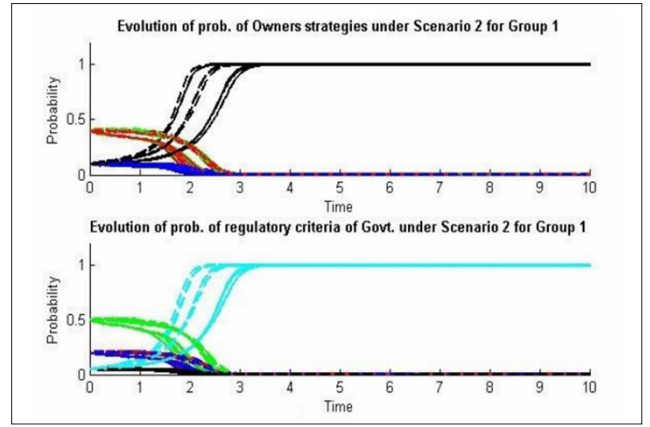

11a)

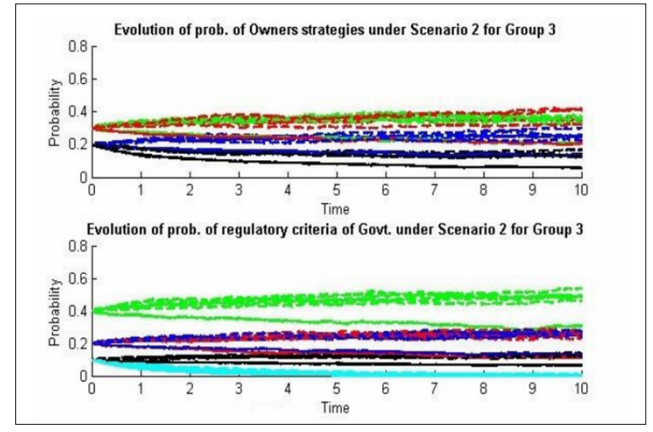

11c)

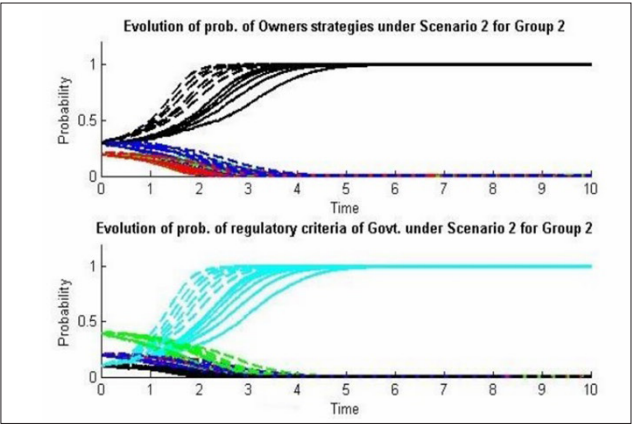

11b)

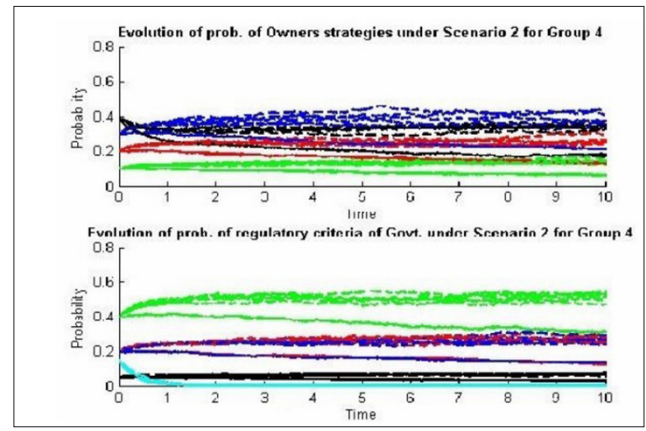

11d)

Figure 11 . The fuzzy stochastic evolutionary process for $G_{1}, G_{2}, G_{3}, G_{4}$ under $S_{2}$ 


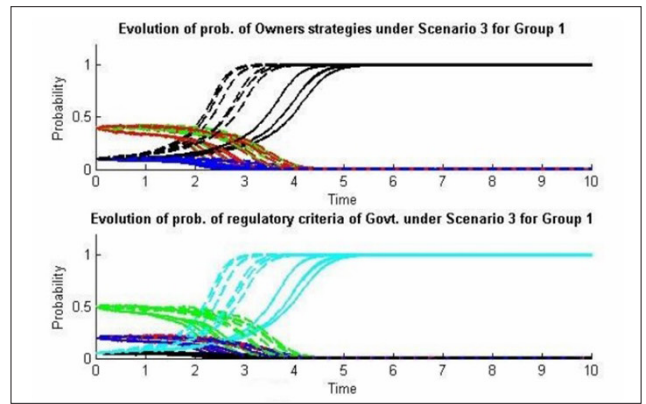

12a)

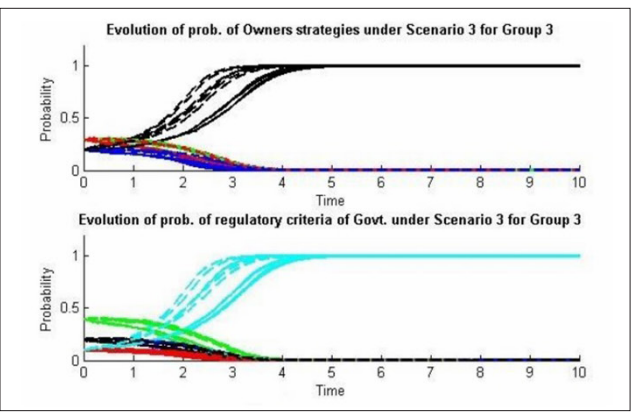

12c)

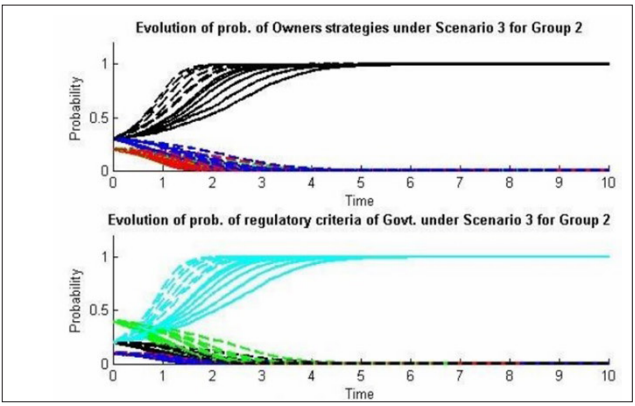

$12 b)$

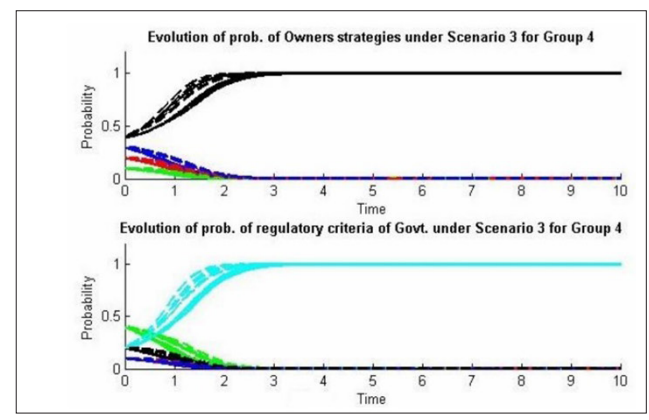

$12 \mathrm{~d})$

Figure 12. The fuzzy stochastic evolutionary process for $G_{1}, G_{2}, G_{3}, G_{4}$ under $S_{3}$

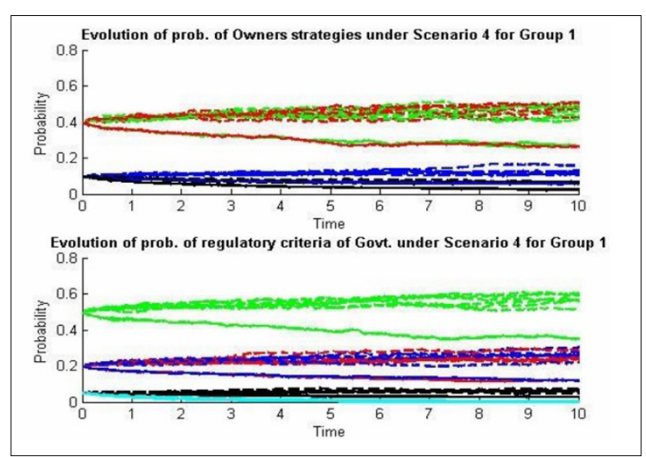

13a)

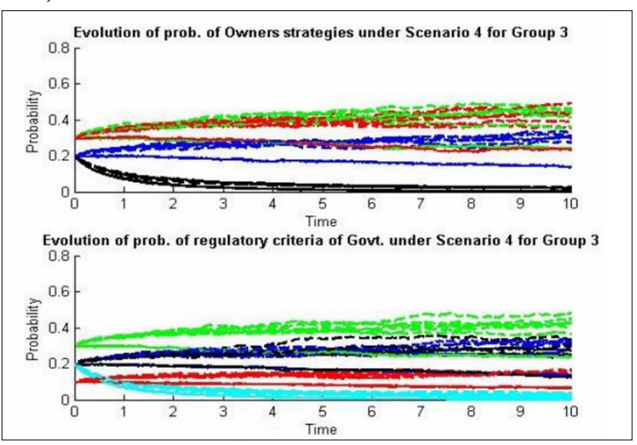

13c)

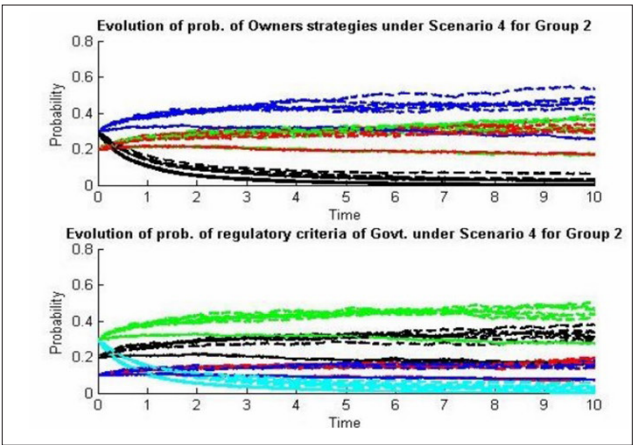

13b)

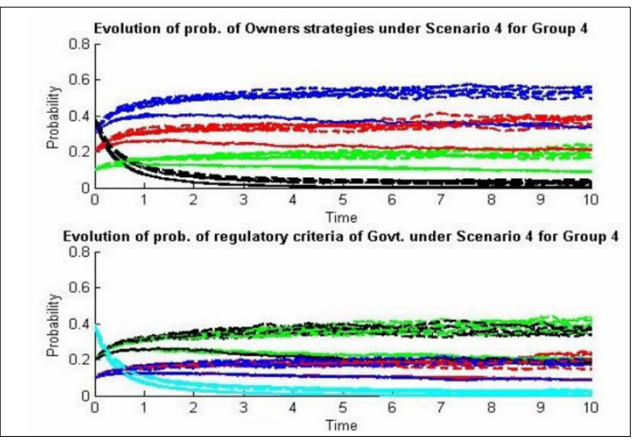

13d)

Figure 13. The fuzzy stochastic evolutionary process for $G_{1}, G_{2}, G_{3}, G_{4}$ under $S_{4}$ 


\subsection{Major implications}

For tea producer, the best alternative strategies are found (Table 7) to be "Development with Pledge" CSR $\left(W_{2}\right)$ in deterministic circumstances, whereas under imprecision of impact of strategy interaction (payoff) the best alternatives are "Development with Pledge CSR" $\left(W_{2}\right)$, "Development with Praiseworthy CSR" $\left(W_{1}\right)$ and "Development with Scattering CSR" $\left(W_{3}\right)$ respectively. Moreover, when imprecise impact of strategy interaction is considered along with market volatility "Development with Praiseworthy CSR" $\left(W_{1}\right)$ and "Development with Pledge CSR" ( $\left.W_{2}\right)$ dominates other strategies for TEO.

For tea board the best alternative strategies are found to be "Increase of Substantive national and international Tea demand" $\left(G_{2}\right)$ in deterministic circumstances, whereas under imprecision of impact of strategy interaction (payoff) the best alternatives are "Increase of Substantive national and international Tea demand" $\left(R_{1}\right)$, "Comprehensive Infrastructure of Tea Industry" $\left(R_{2}\right)$, and "Inclusive Labour Policy" $\left(R_{3}\right)$ respectively. However, under the consideration of imprecise impact of strategy interaction and with market volatility "Increase of Substantive national and international Tea demand" $\left(R_{1}\right)$, "Comprehensive Infrastructure of Tea Industry" $\left(R_{2}\right)$, and "Inclusive Labour Policy" $\left(R_{3}\right)$ respectively. Similarly, for other groups $\left(G_{2}, G_{3}\right.$ and $G_{4}$ ) under different scenarios $\left(S_{2}, S_{3}\right.$ and $\left.S_{4}\right)$ the preferential order of different strategies is shown in the Table 7. The effect of imprecise payoffs (uncertainty in outcome of the pair of strategies $\left(\left(W_{i}, R_{j}\right), i=1,2,3,4 ; j=1,2,3,4,5\right.$. $)$, as well as market volatility is also reported.

It could be concluded from Table 7 that "Development with Pledge CSR $\left(W_{2}\right)$ " and "Development with Praiseworthy CSR $\left(W_{1}\right)$ " are favourable strategies for almost all groups of tea producers whereas in uncertain environment "Development with Scattering CSR $\left(W_{3}\right)$ " could have yield better result for group 2 and group 4 under scenario 1. Furthermore, in this case the tea board should employ strategy "Safeguard of Satisfactory National and International Tea Demand $\left(R_{1}\right)$ " with an invasion of "Wide-ranging assistance to ITE $\left(R_{4}\right)$ " in uncertain circumstances. In case of scenario 2, "Pledge CSR" is the best alternative for all groups except the third one, which should adopt strategy "Praiseworthy CSR". On the contrary of the previous case in uncertain circumstances "Development with Fatigue CSR $\left(W_{4}\right)$ " is most ideal option for group 1 and group 2; whereas "Pledge CSR" and 'Praiseworthy CSR" are most suitable strategies for scenario 3, but "Scattering CSR" is the best alternative for group 4. Under this scenario, "Ample Morality development $\left(R_{5}\right)$ " is the better alternative for group 1 and group 2 though in deterministic condition satisfactory demand will yield better result for group 2. However, "Satisfactory demand and Inclusive Labour Policy $\left(R_{3}\right)$ " would serve better for group 3 and group 4 though in deterministic case "Wide-ranging assistance" and "Satisfactory demand" are better strategies for group 3 and group 4 respectively. For scenario 3, "praiseworthy CSR" is the best strategy for group 1 and group 4 "whereas scattering CSR" serves better for group 2 and group 3 in deterministic case. However, in uncertainty 'fatigue CSR" is the best strategy for all the groups. Wherein if tea board adopts "satisfactory demand" it will serve better for group 1 and group 3 but employing Morality development will boost group 2 and group 4. Herein, "morality development" serves as best option for all the groups in uncertain environment just like "wide-ranging assistance" serves for the ITEs. Finally, in the last scenario "Praiseworthy CSR" is the best alternative for group 1 and group 3 and "Pledge CSR" will boost them in uncertain environment. Similarly, "Pledge CSR" is the 
best alternative for group 2 and group 4 and "scattering CSR" will boost them in uncertain circumstances. Moreover, if tea board employ "satisfactory demand" it will help group 1 and group 3 to grow but adoption of "wide-ranging assistance "will help group 2 and group 4 . However, in uncertain case "satisfactory demand" seems to be the best strategy for all the groups though "Inclusive Labour Policy" also serves better for group 1 and group 3 whereas "wide-ranging assistance" serves better for group 2 and group 4.

From the above simulation outcomes, the following most important suggestions could be summarized as:

(1) The ITI and ITB can work jointly to advance the CSR performance in downstream (those are in group 2 and group 3) tea industries. In multiple-scenarios as regulatory strategy it can be observed that they may affect each other's behaviour. As a result, this can alter the professional strategies of ITI and ITB for the whole market. In practice, a large number of tea industries have accepted policies to face CSR matters for themselves, for example Bagrakota, Dunkun etc.

(2) CSR proficiency is a crucial issue for the collaboration affinity among multiple-scenarios for regulatory purpose in the long term of entrepreneurship. In veracity, this will encourage the development of skills and willingness and implement CSR to workers specifically the Makaibari and Glen burn Tea Company etc.

(3) Results presented in section 5.4 and Table 7 affirm the final selection of strategies of ITI and ITB based on the "unmoved" and "altered" scenarios.

\section{Conclusions}

The sustainability of an economic development model depends on the long term effects of the adopted strategies. As a consequence, a multi-agent decision problem could naturally modelled as an evolutionary game problem. The major concern is to determine the effective decisions (development plans) that could generate better goal (profit) than the others in the long run. In this paper the multi-agent decision problem in ITI is modelled as evolutionary game and the corresponding replicator dynamics is solved to find evolutionary stable strategies (ESS) and evolutionary mixed strategies (EMS). These ESS and EMS are indeed Nash equilibriums of the multi-agent decision problem, which are the set of decisions such that no agent has any benefit by switching his decision in the long run. In the context of multi-agent decision problem these ESSs and EMSs are the sustainable decisions where no agent has any benefit by deviating from it.

Hence this methodology is applicable with any multi-agent decision making problem where more than one agent makes their decision simultaneously and the outcome depends upon the decision of all the agents. However single agent decision problem comes under the class of control problems. Therefore the sustainable evolutionary solutions for any multiagent decision making problem could be obtained by the novel evolutionary game theory based model proposed in this paper.

The evolutionary game dynamics identifies the strategic behaviours which could be sustained in the long run i.e. the strategies which would could wipe out the other strategies evolutionarily. So this approach could assess the impact of different strategic regulations and could identify those which could results better productivity in the long run as sustainable 


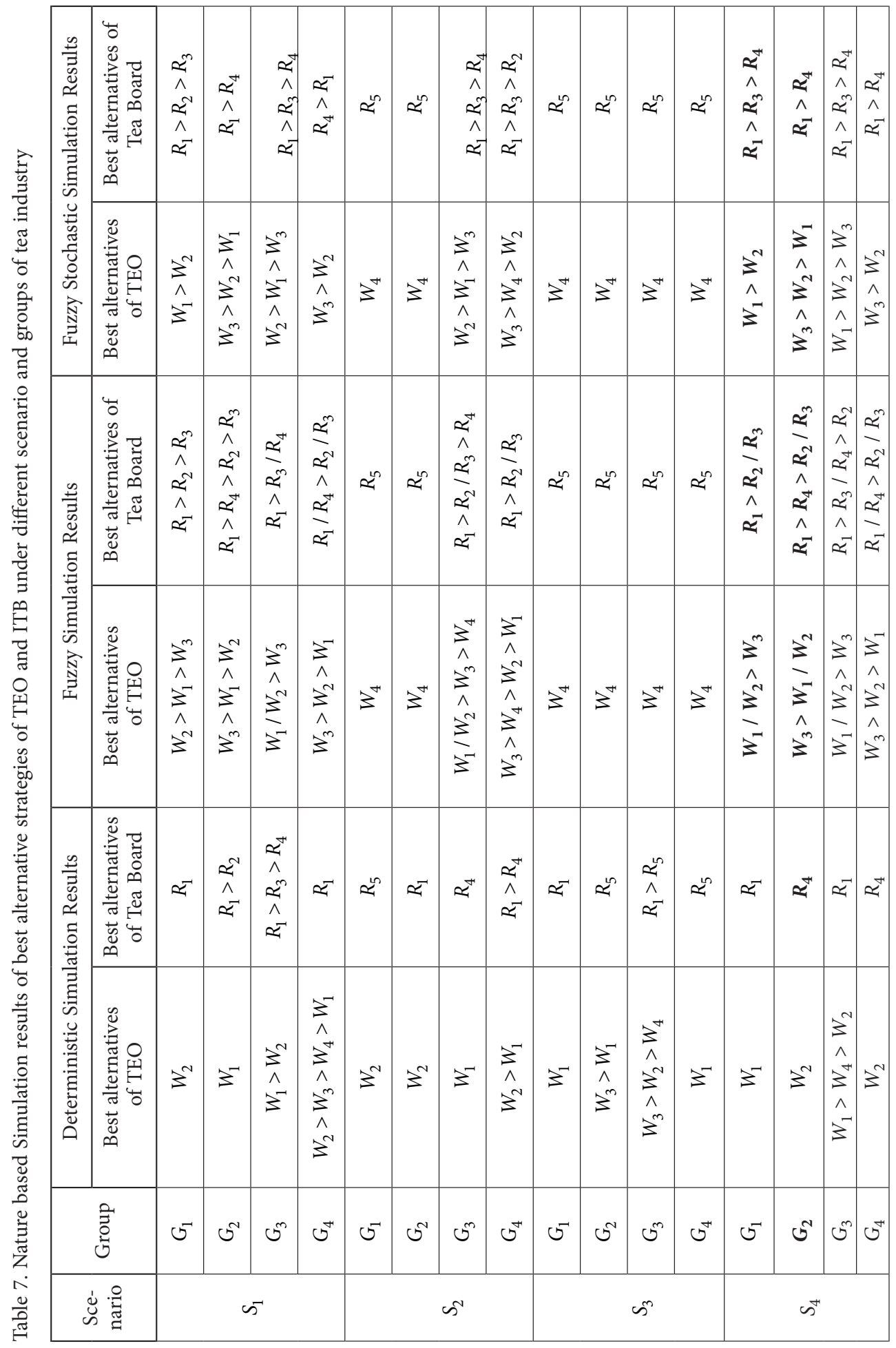


strategies. However the short term impact of strategies may not be properly depicted in this approach. This is the sole limitation of the method.

Moreover, the outcomes of decision strategies are considered to be imprecise in this study whereas the volatility of the market is modelled as stochastic white noise. Hence forth best alternative (sustainable) decision strategies in uncertain circumstances are obtained for multigroup and multi-scenarios decision problem in ITI. The uncertainty on in the outcomes of decisions are considered to be imprecise and modelled as fuzzy evolutionary game based on multi-agent decision making problem. Also fuzzy stochastic evolutionary game model is developed to incorporate the random effect of market volatility. In each cases the replicator dynamics is solved to obtain sustainable strategies and the effect of uncertainties are analysed with the template deterministic system. Further, the simulation results overall matches the CSR activities of different group of tea industries in India which validates our results. The analysis indicates that different group of tea industries can form distinguished pattern of sustainable development with CSR activities under uncertainty.

This study can help tea industries and tea board to propagate effective policies in the long run. The present work could be extended by exploring, such as effect of local community participation as another agent or by considering more socio political constraints. Also the methodology could be applied to some other multi-agent decision making problems with different objectives of the agents in general which could be modelled as multi criteria multiagent decision making problems.

\section{References}

Andreopoulou, Z.; Koliouska, C.; Zopounidis, C. 2017. Multicriteria and clustering: Classification techniques in agrifood and environment. Springer. https://doi.org/10.1007/978-3-319-55565-2

Aplak, H. S.; Türkbey, O. 2013. Fuzzy logic based game theory applications in multi-criteria decision making process, Journal of Intelligent \& Fuzzy Systems 25(2): 359-371.

Bhattacharya, C. B.; Sen, S. 2001. Does doing good always lead to doing better? Consumer reactions to corporate social responsibility, Journal of Marketing Research 28: 225-243.

Cheruiyot, T. K.; Tarus, D. K. 2017. Corporate social responsibility in Kenya: Blessing, curse or necessary evil? Chapter 9, in S. Idowu, S. Vertigans, A. S. Burlea (Eds.). Corporate social responsibility in times of crisis. CSR, sustainability, ethics \& governance. Springer, Cham.

https://doi.org/10.1007/978-3-319-52839-7_9

Debnath, A.; Roy, J.; Kar, S.; Zavadskas, E. K.; Antucheviciene, J. 2017. A hybrid MCDM approach for strategic project portfolio selection of agro by-products, Sustainability 9(8): 1302-1335. https://doi.org/10.3390/su9081302

Deng, X.; Jiang, W.; Zhang, J. 2017. Zero-sum matrix game with payoffs of dempster-shafer belief structures and its applications on sensors, Sensors 17(4): 922. https://doi.org/10.3390/s17040922

Deng, X.; Liu, Q.; Deng, Y. 2016. Matrix games with payoffs of belief structures, Applied Mathematics and Computation 273: 868-879. https://doi.org/10.1016/j.amc.2015.10.056

Deng, X.; Zheng, X.; Su, X.; Chan, F. T.; Hu, Y.; Sadiq, R.; Deng, Y. 2014. An evidential game theory framework in multi-criteria decision making process, Applied Mathematics and Computation 24(4): 783-793. https://doi.org/10.1016/j.amc.2014.07.065

Grant, S.; Quiggin, J. 2017. The evolution of awareness, Journal of Economic Psychology 63: 86-92. https://doi.org/10.1016/j.joep.2017.01.010 
GW. 2009. Environmental hazard of Tea garden belt in Jalpaiguri district, West Bengal [online], [cited 15 November 2016] Geospatial World. Available from Internet: https://www.geospatialworld.net/ article/environmental-hazard-of-tea-garden-belt-in-jalpaiguri-district-west-bengal/

Hilbe, C. 2011. Local replicator dynamics: a simple link between deterministic and stochastic models of evolutionary game theory, Bulletine Mathematical Biology 73(9): 2068-2087. https://doi.org/10.1007/s11538-010-9608-2

IT. 2006. Darjeeling tea's lesson for handlooms [online], [cited 29 October 2017]. Indiatogether. Available from Internet: http://www.indiatogether.org/handloom-economy--2

Kang, Z.; Morin, T. 2016. Multi-attribute decision making in a bidding game with imperfect information and uncertainty, International Journal of Information Technology \& Decision Making 15(01): 63-81. https://doi.org/10.1142/S0219622015500340

Kotler, P.; Lee, N. 2005. Corporate social responsibility: doing the best for your company and your cause. New Jersey, Hoboken, John Wiley \& Sons Inc.

Lazonick, W.; O'Sullivan, M. 2000. Maximizing shareholder value a new ideology for corporate governance, Economy and Society 29(1): 13-35. https://doi.org/10.1080/030851400360541

Madani, K.; Lund, J. R. 2011. A Monte-Carlo game theoretic approach for multi-criteria decision making under uncertainty, Advances in Water Resources 34(5): 607-616.

https://doi.org/10.1016/j.advwatres.2011.02.009

Maynard, S. J.; Prince, G. R. 1973. The Logic of animal conflict, Nature 246: 15-18. https://doi.org/10.1038/246015a0

Mohanty, B. K.; Gupta, M. 2015. Product selection in e-commerce under fuzzy environment: a MADM game theoretic model, International Game Theory Review 17(01): 154-208. https://doi.org/10.1142/S0219198915400083

Nowak, M. A.; May, R. M. 1992. Evolutionary games and spatial chaos, Nature 359: 826-829. https://doi.org/10.1038/359826a0

Nowak, M. A.; Sigmund, K. 2004. Evolutionary dynamics of biological games, Science 303: 793-799. https://doi.org/10.1126/science.1093411

Requejo, R. J.; Camacho, J. 2011. Evolution of cooperation mediated by limiting resources: connecting resource based models and evolutionary game theory, Journal of Theoretical Biology 272(1): 35-41. https://doi.org/10.1016/j.jtbi.2010.12.005

Rosas, A. 2010. Evolutionary game theory meets social science: is there a unifying rule for human cooperation?, Journal of Theoretical Biology 264(2): 450-456. https://doi.org/10.1016/j.jtbi.2010.02.015

Roy, J.; Adhikary, K.; Kar, S. 2016a. Credibilistic TOPSIS model for evaluation and selection of municipal solid waste disposal methods [online], [cited 22 August 2017]. Available from Internet: https://arxiv.org/ftp/arxiv/papers/1606/1606.08965.pdf

Roy, J.; Ranjan, A.; Debnath, A.; Kar, S. 2016b. An extended MABAC for multi-attribute decision making using trapezoidal interval type-2 fuzzy numbers [online], [cited 22 August 2017]. Available from Internet: https://arxiv.org/pdf/1607.01254v4.pdf

Roy, J.; Chatterjee, K.; Bandhopadhyay, A.; Kar, S. 2018. Evaluation and selection of medical tourism sites: A rough analytic hierarchy process based multi attributive border approximation area comparision approach. Expert System 35(1), e12232. https://doi.org/10.1111/exsy.12232

Tirkey, L. 2005. Tea plantations in the Darjeeling district, India: Geo-ecological and socio- economic impacts in post-independence period: Master's thesis. Natural Resource Institute, University of Manitoba.

WTN. 2016. Global tea production 2015 [online], [cited 30 February 2017]. Worldtea News. Available from Internet: http://worldteanews.com/news/global-tea-production-2015\#sthash.CitJt52Y.dpuf| 